\title{
A Novel HPLC-Based Method to Investigate on RNA after Fixation
}

\author{
Paolo Fattorini $\left.{ }^{1}{ }^{(}\right)$, Cristina Forzato ${ }^{2}\left(\mathbb{D}\right.$, Domenico Tierno ${ }^{1,3}$, Eleonora De Martino ${ }^{1}{ }^{(\mathbb{C}}$, \\ Eros Azzalini ${ }^{1}$, Vincenzo Canzonieri ${ }^{1,4} \oplus$, Giorgio Stanta ${ }^{1}$ and Serena Bonin ${ }^{1, *}$ \\ 1 DSM-Department of Medical Sciences, University of Trieste, 34149 Trieste, Italy; fattorin@units.it (P.F.); \\ domenico.tierno@phd.units.it (D.T.); edemartino@units.it (E.D.M.); eazzalini@units.it (E.A.); \\ vcanzonieri@cro.it (V.C.); stanta@impactsnetwork.eu (G.S.) \\ 2 Department of Chemical and Pharmaceutical Sciences, University of Trieste, 34127 Trieste, Italy; \\ cforzato@units.it \\ 3 Doctorate of Nanotechnology, University of Trieste, 34100 Trieste, Italy \\ 4 Pathology Unit, IRCCS CRO Aviano-National Cancer Institute, 33081 Aviano, Italy \\ * Correspondence: sbonin@units.it; Tel.: +39-040-399-3266
}

Received: 27 August 2020; Accepted: 9 October 2020; Published: 13 October 2020

\begin{abstract}
RNA isolated from fixed and paraffin-embedded tissues is widely used in biomedical research and molecular pathology for diagnosis. In the present study, we have set-up a method based on high performance liquid chromatography (HPLC) to investigate the effects of different fixatives on RNA. By the application of the presented method, which is based on the Nuclease S1 enzymatic digestion of RNA extracts followed by a HPLC analysis, it is possible to quantify the unmodified nucleotide monophosphates (NMPs) in the mixture and recognize their hydroxymethyl derivatives as well as other un-canonical RNA moieties. The results obtained from a set of mouse livers fixed/embedded with different protocols as well from a set of clinical samples aged 0 to 30 years-old show that alcohol-based fixatives do not induce chemical modification of the nucleic acid under ISO standard recommendations and confirm that pre-analytical conditions play a major role in RNA preservation.
\end{abstract}

Keywords: RNA; fixation; nuclease digestion; nucleotide-monophosphate; HPLC; degradation; modification; hm-NMP; ISO standards

\section{Introduction}

Clinical samples from surgery and biopsy procedures are fixed for histopathological analysis. The aim of fixation is to preserve tissues permanently in as lifelike a state as possible and to make it possible to generate thin stained sections. In the past, an optimal morphological preservation was the sole requirement for fixation, whereas nowadays nucleic acids preservation for onco-pathology has also become an important requisite for gene expression profiling and sequencing aimed at defining reliable diagnostic and prognostic parameters [1]. The $4 \%$ aqueous solution of formaldehyde (formalin) is the most widely used fixative in histopathology. However, in the past also Bouin's solution was also applied in certain hospitals for its ability to preserve some morphological details, such as nuclear conformation [2]. In recent years, because of the need of higher quality biomolecules, commercial alcohol-based fixatives have been developed, such as RCL2 [3], FineFix [4], Paxgene [5]. In the above scenario, it is well-known that in formalin-fixed and Bouin's fixed samples the quality of nucleic acid is lower than in alcohol-based fixatives [4-6] and that formalin fixation has led to the formation of mono-methylol adducts (hydroxymethyl derivatives) in nucleic acids and proteins and cross-links between them [7]. Nonetheless, for other fixatives, included Bouin's solution, their effect in modifying 
nucleic acids remains unknown and the amount of un-modified nitrogenous bases in the extracts have not been taken into account.

We here describe a novel method based on high performance liquid chromatography (HPLC) that is aimed at investigating on the amount of unmodified nitrogenous bases in RNA extracts obtained from different procedures of fixation.

\section{Results}

To set-up the HPLC-based method to detect unmodified nucleotide monophosphates (NMPs) in RNA extracts, we first set-up the experimental conditions to quantify each unmodified NMP by HPLC and subsequently we investigated methods to degrade RNA into NMPs. The study design is divided into three main sections, as described in Figure 1.

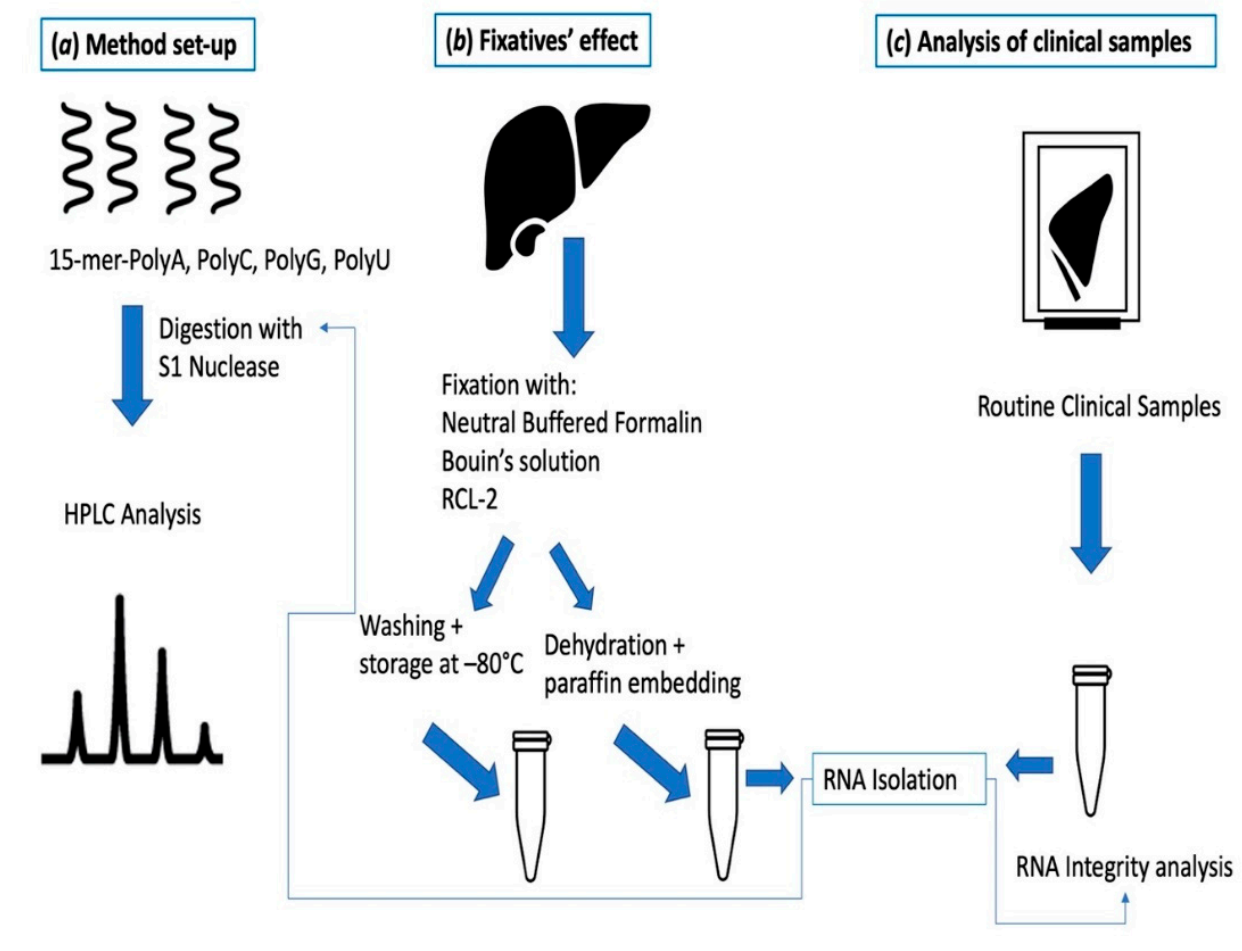

Figure 1. Design of the study: (a) Method set-up for the optimization of the digestion conditions and HPLC separation using 15-mer-mono-oligonuclotides; (b) Study on fixatives' effect based on the treatment of the same tissues (mouse livers) with 3 different fixatives and application of the HPLC method to RNA extracts; (c) Application of the HPLC method to RNA obtained from routine clinical samples. In sections $(\mathbf{b}, \mathbf{c})$, after isolation, RNA is parallelly submitted to digestion followed by HPLC analysis and to integrity analysis.

During the procedure's set-up, hydroxymethyl derivatives of the NMPs were also synthetized as reported in the Appendix A. They were characterized by ${ }^{1} \mathrm{H}$ NMR and by HPLC (Appendix A). Their synthesis sought to prove that the hydroxymethyl derivatives (hm-derivatives) of the NMP do not overlap with those that remained unmodified during HPLC analysis.

\subsection{HPLC Analysis-Quantification of NMPs and Resolution of NMPs and hm-NMPs}

A HPLC method was set-up to separate both mononucleotides and their hydroxymethyl derivatives as described in the material and methods section. In order to quantify unmodified NMP, calibration curves with correlation coefficients $\mathrm{R}^{2}>0.999$ were obtained for each NMP in tests carried out at least in triplicate. The recovery percentage of each NMP and results of the calibration analysis are reported in Table 1. 
Table 1. Results of the calibration curves: recovery percentage as ratio of the recovered amount from HPLC vs. the loaded one, results of the regression analysis, LRE (Linear Regression Equation) LOD (limit of detection) and LOQ (limit of quantification).

\begin{tabular}{ccccc}
\hline Variables & CMP & UMP & GMP & AMP \\
\hline $130 \mathrm{ng} / \mu \mathrm{L}$ & $98 \pm 1^{1}$ & $99 \pm 1$ & $98 \pm 1$ & $97 \pm 1$ \\
$65 \mathrm{ng} / \mu \mathrm{L}$ & $98 \pm 1$ & $98 \pm 1$ & $98 \pm 1$ & $99 \pm 1$ \\
$39 \mathrm{ng} / \mu \mathrm{L}$ & $98 \pm 1$ & $99 \pm 1$ & $95 \pm 1$ & $98 \pm 1$ \\
$13 \mathrm{ng} / \mu \mathrm{L}$ & $97 \pm 1$ & $97 \pm 1$ & $93 \pm 1$ & $93 \pm 1$ \\
$1.3 \mathrm{ng} / \mu \mathrm{L}$ & $91 \pm 4$ & $98 \pm 2$ & $90 \pm 3$ & $92 \pm 3$ \\
$\mathrm{LRE}$ & $5.8 \times 10^{-5} \times-3.9 \times 10^{-4}$ & $4.6 \times 10^{-5} \times+8.4 \times 10^{-5}$ & $4.6 \times 10^{-5} \times-1.0 \times 10^{-3}$ & $2.5 \times 10^{-5} \times-2.8 \times 10^{-4}$ \\
$\mathrm{R}^{2}$ & $>0.999$ & $>0.999$ & $>0.999$ & $>0.999$ \\
$\mathrm{LOQ}(\mathrm{ng} / \mu \mathrm{L}) 10(\sigma / \mathrm{s})^{1}$ & 7.1 & 4.4 & 14.9 & 11.2 \\
$\mathrm{LOD}(\mathrm{ng} / \mu \mathrm{L}) 3.3(\sigma / \mathrm{s})$ & 2.3 & 1.4 & 4.9 & 3.8 \\
\hline
\end{tabular}

${ }^{1}$ standard deviation/noise.

Formalin fixation modifies nucleic acids by the addition of a mono-methylol group $\left(\mathrm{CH}_{2}-\mathrm{OH}\right)$ to the nitrogenous bases [7]. Synthetic hm-derivatives (see Appendix A) were synthetized and submitted to HPLC analysis (see Table 2 and Figure A2). To verify the resolution of NMPs and their hm-derivatives, based on the treatment of NMPs with $4 \%$ neutral buffered formalin, a mixture of UMP and CMP/hm-CMP (Figure 2a), and AMP/hmAMP and GMP/hm-GMP (Figure 2c) were submitted to HPLC analysis. Furthermore, spiking the specific NMP to hm-derivatives as shown in Figure $2 b$ for UMP and CMP/hm-CMP and in Figure 2d for AMP/hm-AMP and GMP/hm-GMP, respectively. Overall, the resolution of NMPs and hm-NMPs is shown in Figure 2e where a mixture of the four NMPs and their hm-NMPs was successfully separated by HPLC. Of note, UMP does not apparently react with $4 \%$ neutral buffered formalin, as shown in the $1 \mathrm{H}-\mathrm{NMR}$ spectra in the Appendix $\mathrm{A}$ and in chromatograms in Figure 2a,b,e.

The retention times of the four NMP and the three hm-NMP are reported in Table 2, which shows that the $\mathrm{CV} \%$ was always $<7.3 \%$ in intra-session experiments, whereas higher values in inter-session were due both to the exhaustion of the solid phase and to the effect of room temperature in a non-thermostated HPLC apparatus.

Table 2. Retention times (RT) for each NMP and hm-NMP detected in the analytical sessions; $n$ represents the number of detections, RT represents the retention time in minutes, in brackets are reported the coefficients of variation $(\mathrm{CV})$.

\begin{tabular}{|c|c|c|c|c|c|c|c|c|c|c|c|c|c|c|}
\hline \multirow{2}{*}{$\begin{array}{l}\text { Analytical } \\
\text { Session }\end{array}$} & \multicolumn{2}{|c|}{ CMP } & \multicolumn{2}{|c|}{ Hm-CMP } & \multicolumn{2}{|c|}{ UMP } & \multicolumn{2}{|c|}{ AMP } & \multicolumn{2}{|c|}{ Hm-AMP } & \multicolumn{2}{|c|}{ GMP } & \multicolumn{2}{|c|}{ Hm-GMP } \\
\hline & $n$ & RT & $n$ & RT & $n$ & RT & $n$ & RT & $n$ & RT & $n$ & RT & $n$ & RT \\
\hline $1^{\circ}-02 / 2019$ & 45 & $\begin{array}{c}6.0 \\
(2.3)\end{array}$ & 3 & $\begin{array}{c}7.8 \\
(0.4)\end{array}$ & 42 & $\begin{array}{c}8.2 \\
(2.9)\end{array}$ & 45 & $\begin{array}{l}28.2 \\
(7.3)\end{array}$ & 3 & $\begin{array}{l}46.3 \\
(0.4)\end{array}$ & 45 & $\begin{array}{l}12.0 \\
(4.1)\end{array}$ & 24 & $\begin{array}{l}22.1 \\
(6.7)\end{array}$ \\
\hline $2^{\circ}-04 / 2019$ & 18 & $\begin{array}{c}5.8 \\
(0.8)\end{array}$ & 0 & - & 18 & $\begin{array}{c}7.9 \\
(1.5)\end{array}$ & 18 & $\begin{array}{l}26.1 \\
(4.1)\end{array}$ & 0 & - & 17 & $\begin{array}{l}11.5 \\
(2.1)\end{array}$ & 12 & $\begin{array}{l}20.8 \\
(3.4)\end{array}$ \\
\hline $3^{\circ}-07 / 2019$ & 24 & $\begin{array}{c}5.8 \\
(2.4)\end{array}$ & 0 & - & 24 & $\begin{array}{c}7.8 \\
(3.8)\end{array}$ & 24 & $\begin{array}{l}25.9 \\
(7.1)\end{array}$ & 0 & - & 24 & $\begin{array}{l}11.3 \\
(5.6)\end{array}$ & 6 & $\begin{array}{c}21 \\
(3.3)\end{array}$ \\
\hline $4^{\circ}-02 / 2020$ & 27 & $\begin{array}{c}5.4 \\
(4.0)\end{array}$ & 6 & $\begin{array}{c}6.5 \\
(1.4)\end{array}$ & 27 & $\begin{array}{c}7.1 \\
(2.6)\end{array}$ & 24 & $\begin{array}{l}21.9 \\
(5.8)\end{array}$ & 3 & $\begin{array}{l}40.8 \\
(0.3)\end{array}$ & 27 & $\begin{array}{l}10.1 \\
(3.6)\end{array}$ & 18 & $\begin{array}{l}18.5 \\
(7.0)\end{array}$ \\
\hline $5^{\circ}-06 / 2020$ & 17 & $\begin{array}{c}5.3 \\
(1.3)\end{array}$ & 0 & - & 17 & $\begin{array}{c}6.8 \\
(2.5)\end{array}$ & 19 & $\begin{array}{l}20.35 \\
(7.1)\end{array}$ & 6 & $\begin{array}{l}34.1 \\
(0.3)\end{array}$ & 19 & $\begin{array}{l}9.52 \\
(4.8)\end{array}$ & 12 & $\begin{array}{l}17.5 \\
(5.7)\end{array}$ \\
\hline $6^{\circ}-08 / 2020$ & 4 & $\begin{array}{c}5.2 \\
(1.4)\end{array}$ & 2 & $\begin{array}{c}6.2 \\
(0.9)\end{array}$ & 4 & $\begin{array}{c}6.6 \\
(0.8)\end{array}$ & 4 & $\begin{array}{l}19.0 \\
(0.6)\end{array}$ & 2 & $\begin{array}{l}28.3 \\
(0.8)\end{array}$ & 4 & $\begin{array}{l}9.04 \\
(0.9)\end{array}$ & 4 & $\begin{array}{l}16.05 \\
(1.2)\end{array}$ \\
\hline Total & 135 & $\begin{array}{c}5.7 \\
(5.4)\end{array}$ & 11 & $\begin{array}{c}6.7 \\
(9.4)\end{array}$ & 132 & $\begin{array}{l}7.6 \\
(7.7)\end{array}$ & 134 & $\begin{array}{l}25.0 \\
(14.1)\end{array}$ & 14 & $\begin{array}{l}36.7 \\
(17.6)\end{array}$ & 134 & $\begin{array}{l}11.0 \\
(9.8)\end{array}$ & 79 & $\begin{array}{c}20.2 \\
(12.2)\end{array}$ \\
\hline
\end{tabular}




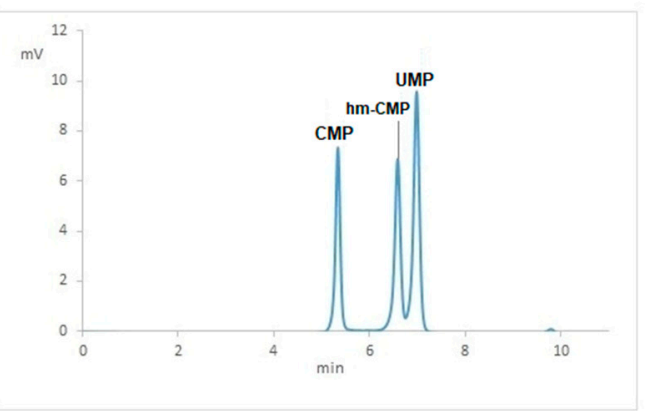

(a)

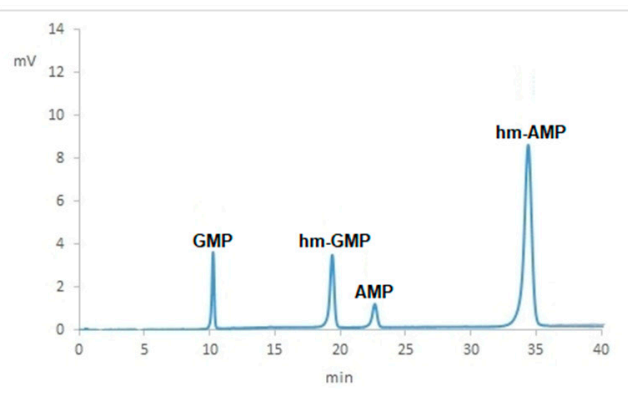

(c)

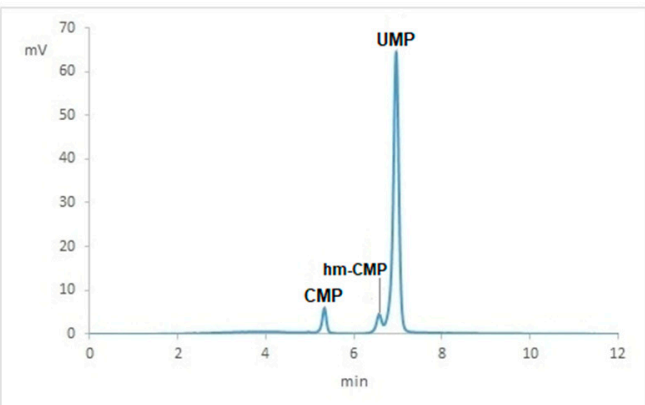

(b)

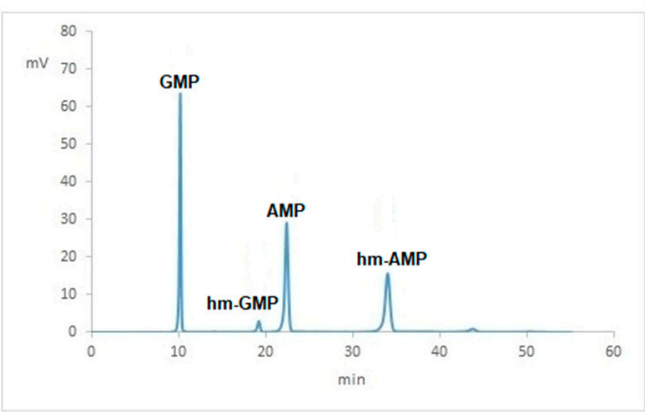

(d)

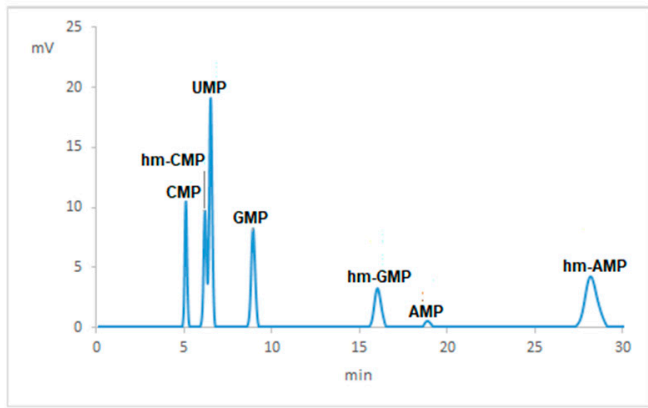

(e)

Figure 2. Resolution of NMPs and hm-NMPs by HPLC analysis: (a) Mixture of CMP and UMP treated with $4 \%$ neutral buffered formaldehyde; (b) the same mixture of (a) with the addition of UMP; (c) mix of GMP and AMP treated with $4 \%$ neutral buffered formaldehyde; (d) the mixture of (c) with the addition of AMP and GMP; (e) mixture of the four NMPs treated with $4 \%$ neutral buffered formaldehyde.

\subsection{RNA Digestion Set-Up}

Hydrolysis of the nucleic acids can be achieved both by physical-chemical and enzymatic procedures [8-12]. In keeping with the aim of the present study, physical-chemical procedures involving samples heating were avoided as they can release mono-methylol adducts from the RNA chain thus interfering with the reliability of the HPLC analysis. Consequently, enzymatic reactions with S1 Nuclease (Promega) which cleaves the RNA molecule to 5'-mono-nucleotide were preferred. Digestion conditions were assessed using 15-mer mono-oligonucleotides, namely polyA, polyC, polyG and polyU followed by HPLC separation as shown in Figure 3 and Table 3.

Figure 3 shows that after incubation with S1 nuclease of the 15-mer mono-oligonucleotides they were digested into the specific NMP. Minimal amount of the cyclic forms of each NMP were also detected [13].

To confirm our findings, a standard RNA, as provided by Celbio, after digestion with S1 nuclease returned the expected four peaks at the defined retention times. For the following quantification analyses, a reaction blank including a solution of S1 Nuclease (Promega) in $1 \times$ digestion buffer was injected 
into HPLC to identify peaks related to non-template control as shown in Appendix A-Figure A3. Those signals were subtracted from the following chromatograms for quantification.

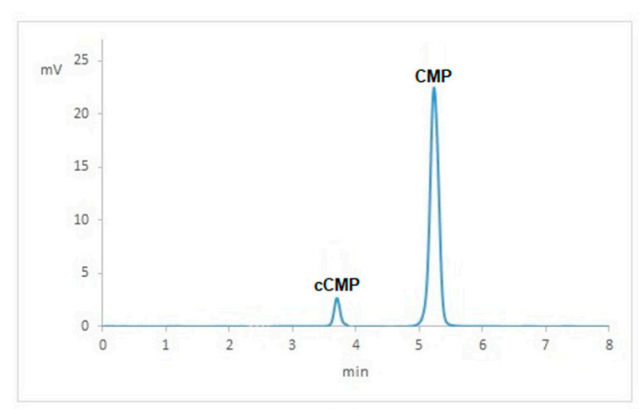

(a)

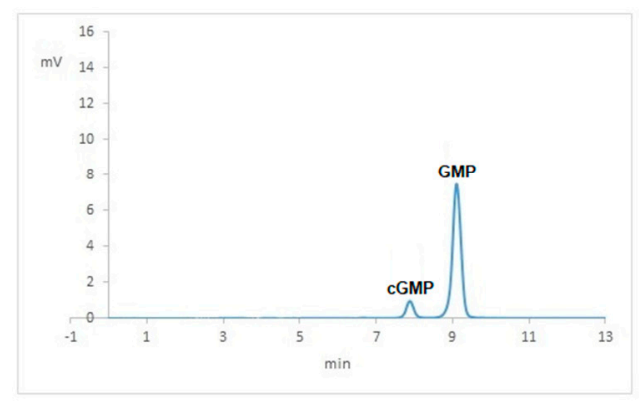

(c)

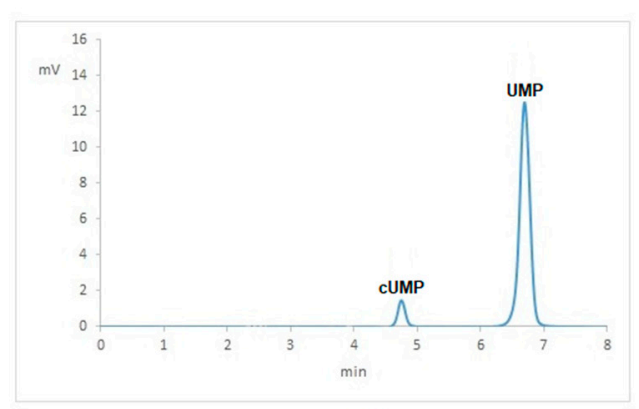

(b)

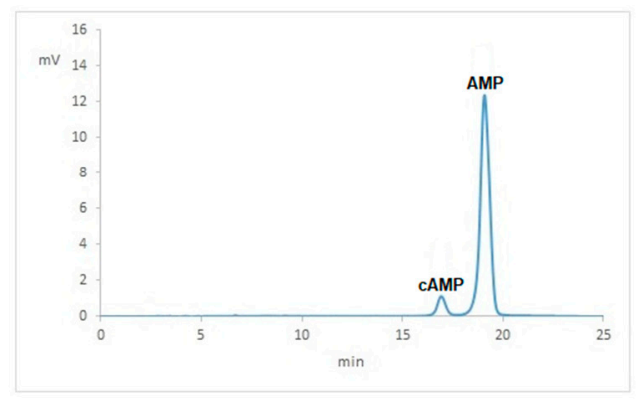

(d)

Figure 3. HPLC analysis of digested 15-mer mono-oligonucleotides: Chromatogram of digestions of polyC (a), polyU (b), polyG (c), polyA (d).

Table 3. Results of the digestion by S1 Nuclease of each polyNMP: recovery percentage as ratio of the recovered amount from HPLC vs. the loaded one and ratio between NMP and cNMP (cyclic NMP) areas.

\begin{tabular}{ccccc}
\hline Variables & CMP & UMP & GMP & AMP \\
\hline PolyC & $93 \pm 1$ & & & \\
PolyU & & $91 \pm 1$ & & \\
PolyG & & & $89 \pm 1$ & \\
PolyA & & & & $92 \pm 1$ \\
NMP/cNMP & $8.6 \pm 1$ & $9.0 \pm 1$ & $10.7 \pm 1$ & $7.3 \pm 1$ \\
\hline
\end{tabular}

\subsection{Fixatives Conditions in Mouse Livers}

The aim of the present study was to apply the HPLC method to fixed samples. To this end, mouse livers were used for the analysis set-up. Mouse livers were submitted to different fixation procedures for $24 \mathrm{~h}$, namely neutral buffered formalin, Bouin's solution and RCL2 ${ }^{\circledR}$, with and without paraffin embedding in comparison to untreated samples (frozen specimen) following ISO standard for pre-analytical processes [14].

Each HPLC analysis was carried out in triplicate loading 600-700 ng of digested RNA in each injection. Chromatograms, where peaks related to the blank were subtracted, are shown in Figure 4. In mouse livers treated with $4 \%$, neutral buffered formalin different digestion patterns were detected showing more than four canonical peaks of unmodified NMPs (Figure $4 \mathrm{~b}, \mathrm{e}$ ). In Table 4 are reported the percentage area of unmodified nucleotide monophosphates detected in the chromatograms. 


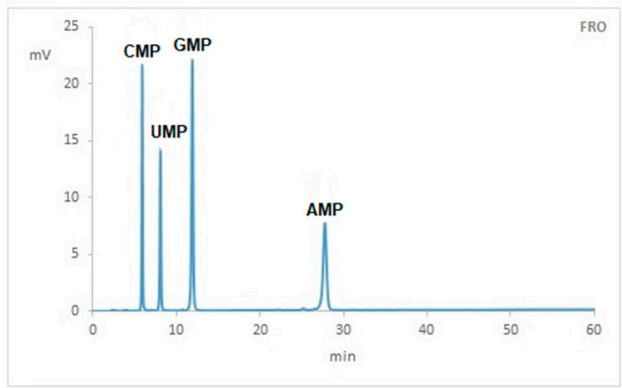

(a)

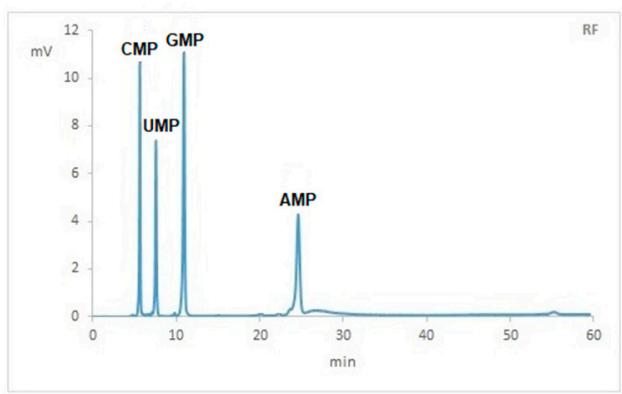

(c)

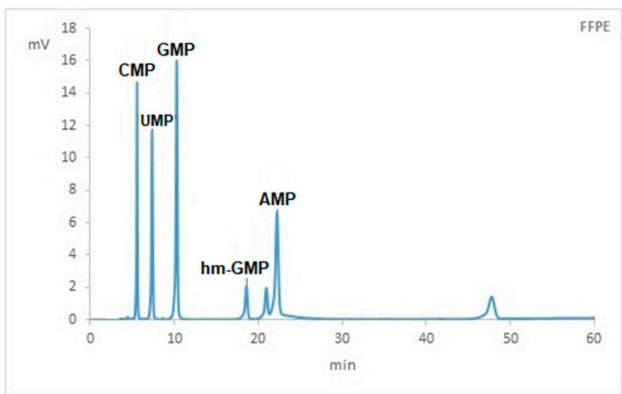

(e)

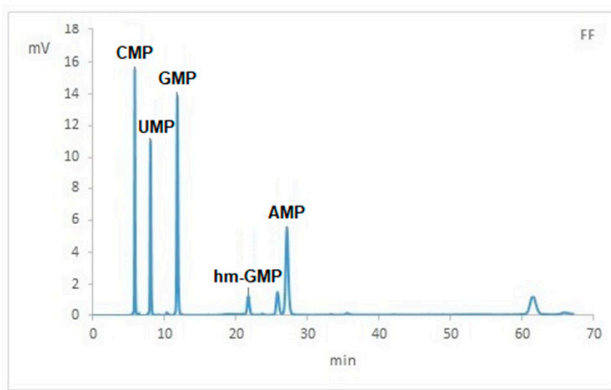

(b)

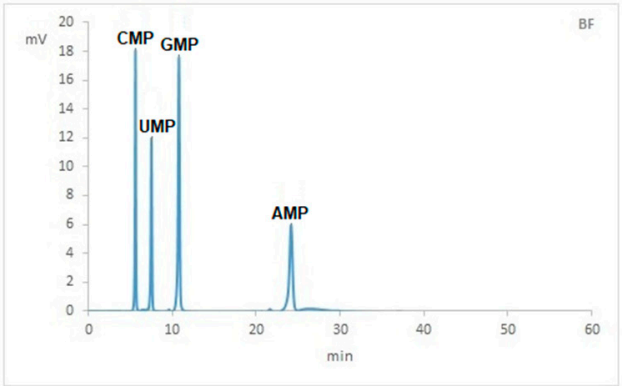

(d)

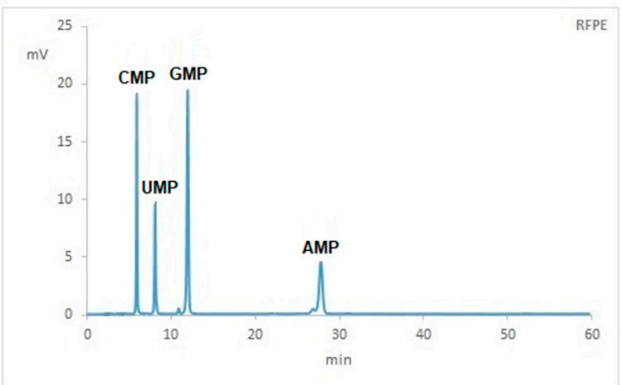

$(f)$

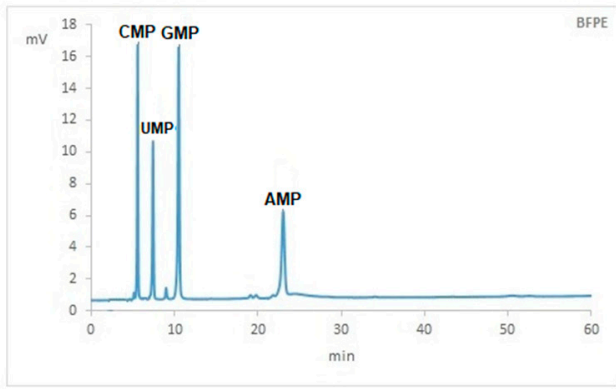

(g)

Figure 4. HPLC analysis of mouse livers submitted to different treatments: Chromatograms of (a) Fresh frozen (Fro); (b) $24 \mathrm{~h}$ in neutral buffered formalin (FF); (c) $24 \mathrm{~h}$ in RCL2 (RF); (d) $24 \mathrm{~h}$ in Bouin's solution (BF); (e) $24 \mathrm{~h}$ in neutral buffered formalin and paraffin-embedded (FFPE); (f) $24 \mathrm{~h}$ in RCL2 and paraffin-embedded (RFPE); (g) $24 \mathrm{~h}$ in Bouin's solution and paraffin-embedded (BFPE). Uncanonical RNA moieties are detected in mouse livers treated with $4 \%$ neutral buffered formalin. 
Table 4. Amount in percentage area of unmodified nucleotide monophosphates identified in the first set of samples as detected by chromatograms.

\begin{tabular}{cccccc}
\hline Sample $^{1}$ & CMP & UMP & GMP & AMP & TOT \\
\hline Frozen & $21 \pm 1 \%$ & $18 \pm 1 \%$ & $35 \pm 1 \%$ & $26 \pm 1 \%$ & $100 \pm 1 \%$ \\
FF & $21 \pm 3 \%$ & $17 \pm 2 \%$ & $26 \pm 1 \%$ & $21 \pm 3 \%$ & $85 \pm 3 \%$ \\
RF & $21 \pm 1 \%$ & $17 \pm 1 \%$ & $38 \pm 1 \%$ & $24 \pm 1 \%$ & $99 \pm 1 \%$ \\
BF & $21 \pm 1 \%$ & $18 \pm 1 \%$ & $37 \pm 1 \%$ & $24 \pm 1 \%$ & $100 \pm 1 \%$ \\
FFPE & $15 \pm 1 \%$ & $16 \pm 1 \%$ & $28 \pm 1 \%$ & $22 \pm 1 \%$ & $80 \pm 1 \%$ \\
RFPE & $21 \pm 3 \%$ & $15 \pm 1 \%$ & $32 \pm 3 \%$ & $20 \pm 1 \%$ & $88 \pm 5 \%$ \\
BFPE & $21 \pm 1 \%$ & $16 \pm 1 \%$ & $38 \pm 1 \%$ & $21 \pm 2 \%$ & $96 \pm 1 \%$
\end{tabular}

${ }^{1}$ FF Formalin-fixed, RF RCL-2 fixed, BF Bouin's fixed, FFPE Formalin-fixed and paraffin-embedded, RFPE RCL-2 fixed and paraffin-embedded, BFPE Bouin's fixed and paraffin-embedded.

Regarding hm-NMPs, the chromatograms in Figure 4 reveal among peaks, only hm-GMP in samples treated with formalin (Figure $4 \mathrm{~b}, \mathrm{e}$, respectively). The ratio of the peaks areas between $\mathrm{hm}-\mathrm{GMP}$ and GMP was about 0.21 . No other peaks referring to $\mathrm{hm}$-nucleotide monophosphates were recorded in FF and FFPE samples. In RCL2 treated samples as well as in Bouin's treated samples, peaks attributable to hm-derivatives were not identified.

\subsection{RNA Quantification and Integrity from Mouse Livers}

RNA purity was measured through the A260/280 and A260/230 ratios by the NanoDrop ${ }^{\text {TM }}$ ND-1000. The mean A260/280 ratio was 1.98 (range 1.70-2.10), reaching the lower value in BF liver specimen. A260/230 ratio was similar in all samples with an average of 2.11 (range 2.07-2.14) as reported in Table 5.

Table 5. Results of RNA quantification and integrity detection by BioAnalyzer in mouse livers.

\begin{tabular}{cccc}
\hline Samples $^{1}$ & A260/A280 & A260/A230 & RIN \\
\hline Frozen & 2.10 & 2.07 & 4.0 \\
FF liver & 1.95 & 2.14 & 2.1 \\
BF liver & 1.70 & 2.09 & N.A. $^{2}$ \\
RF liver & 2.09 & 2.12 & 2.2 \\
FFPE liver & 2.02 & 2.12 & 2.2 \\
BFPE liver & 1.93 & 2.14 & 2.4 \\
RFPE liver & 2.05 & 2.11 & 1.7 \\
\hline
\end{tabular}

${ }^{1}$ FF Formalin-fixed, BF Bouin's fixed, RF RCL-2 fixed, FFPE Formalin-fixed and paraffin-embedded, BFPE Bouin's fixed and paraffin-embedded, RFPE RCL-2 fixed and paraffin-embedded. ${ }^{2}$ N./A. not assessable.

Integrity of RNA extracts was investigated by the Agilent 2100 Bioanalyzer (Agilent Technologies; Santa Clara, CA, USA) recording the RIN number and quantifying the different RNA fragments (see Supplementary Materials for the Gel-like images of the BioAnalayzer runs). Mean RIN number was 2.1 for fixed as well as fixed and embedded samples, but only the Bouin's fixed sample did not return any value and RCL2 fixed and embedded sample had the lowest RIN value (Table 5). As already shown [15] electrophoretic approaches are not particularly sensitive to more seriously degraded RNA such as the ones from fixed samples, although PERM [16] and DV [17] algorithms have been proposed for a better application of the method. RIN values reflect the quality of rRNA rather than mRNA.

The relative amount of RNA stretches was retrieved by the fragment size analysis using the Agilent 2100 Bioanalyzer. Stretches of 60-149 nt prevailed in Bouin's fixed mouse livers, in spite of the embedding process. On the contrary, for formalin and RCL2 a comparable amount of 60-149 nt and 150-299 nt fragments were observed, as shown in Figure 5. In frozen sample, most fragments (85\%) were over 300 bases long. 


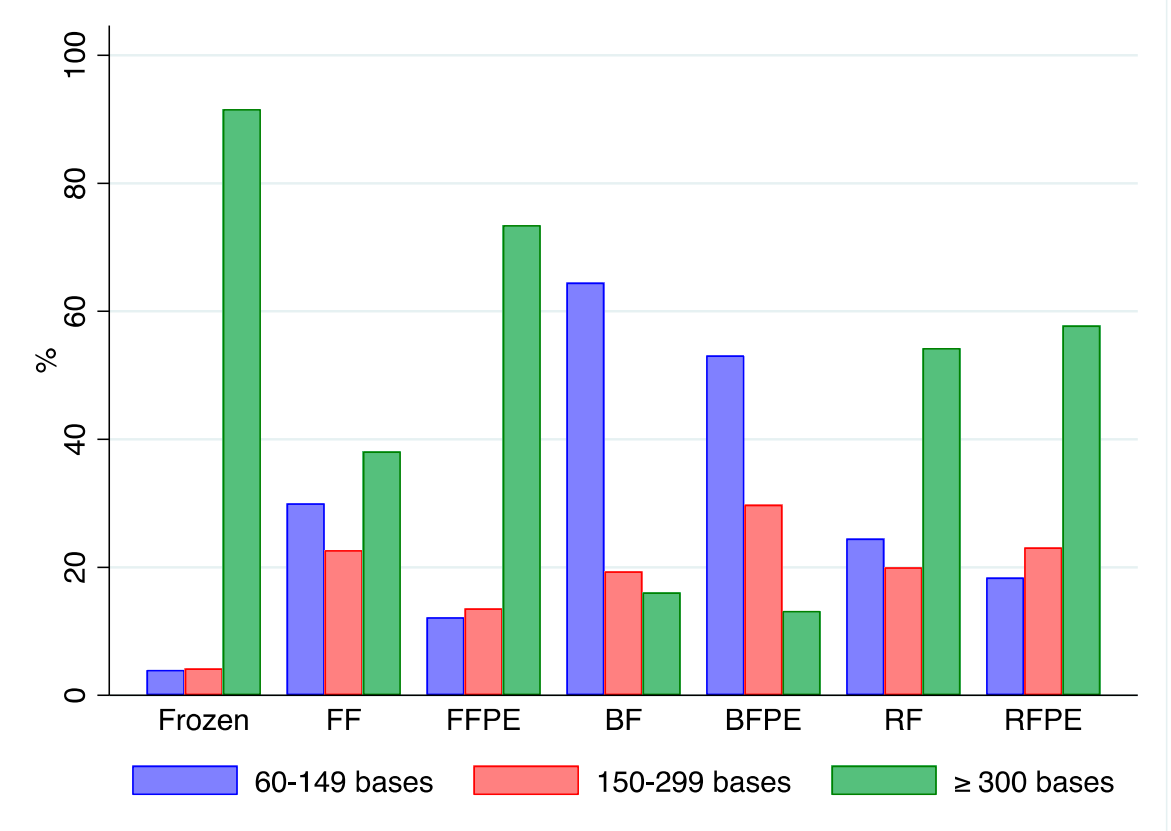

Figure 5. Analysis of RNA fragments length: Bar plots representing the distribution of 60-149, 150-299 bases and equal to or over 300 bases fragments by BioAnalyzer method in fresh frozen, FF formalin-fixed, FFPE formalin-fixed and paraffin-embedded, BF Bouin's solution fixed, BFPE Bouin fixed and paraffin-embedded, RF RCL2 fixed and RFPE RCL2 fixed and paraffin-embedded mouse livers. A higher fragmentation is observed in Bouin's solution fixed samples (BF and BFPE, respectively).

In addition, the RNA integrity was investigated in mouse livers tissue by amplifying different stretches of the cytochrome C oxidase I, mitochondrial (mt-CO1) gene (NC_005089.1) [18], characterized by different lengths. The linear regression lines were obtained by plotting the $\mathrm{Ct}$ versus the amplicon size as shown in Figure 6. RNA stretches of mt-CO1 were amplifiable in all fixed and fixed-paraffin-embedded samples, but Bouin's ones where the maximum amplifiable size was 179 bases. Furthermore, Bouin's fixed samples had higher Ct values.

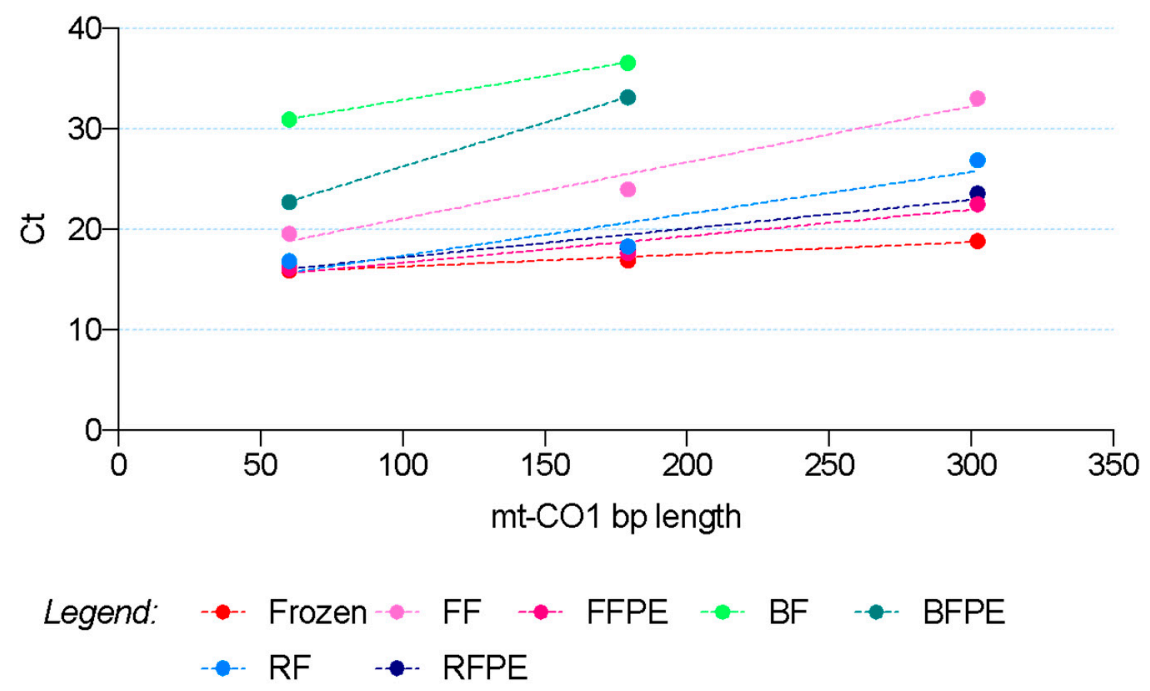

Figure 6. RT-qPCR of mouse livers samples: Linear regression lines obtained plotting the threshold cycle $(\mathrm{Ct})$ by RT-qPCR for mitochondrially encoded cytochrome c oxidase I (mt-CO1) versus the amplicon length (bases) in mouse livers extracts. In Bouin's solution, fixed samples (BF and BFPE, respectively) fragments of 300 bases were not amplifiable. 
In an overall comparison, only the intercepts resulted as being significantly different among pre-analytical treatments $(p<0.0001$, Table 6$)$. This notwithstanding, in performing a Bonferroni multiple comparison analysis, the BFPE slope was significantly different from the FFPE, RFPE and Frozen ones ( $p=0.03, p=0.04$ and $p=0.01$, respectively). The FFPE and RFPE slopes were closer to the slope of the fresh frozen sample (Table 6). Overall, the performance of RT-PCR resulted better in fixed and paraffin-embedded specimens in comparison to fixed ones.

Table 6. Results of the regression analysis for mt-CO1 amplification by RT-qPCR.

\begin{tabular}{ccccccccc}
\hline & Frozen & FF & BF & RF & FFPE & BFPE & RFPE & $p^{\mathbf{1}}$ \\
\hline Slope & 0.01 & 0.06 & 0.05 & 0.04 & 0.03 & 0.09 & 0.03 & 0.14 \\
Y-intercept & 15.08 & 15.50 & 28.14 & 13.20 & 14.04 & 17.50 & 14.40 & $<0.0001$ \\
$\mathrm{R}^{2}$ & 0.97 & 0.96 & & 0.86 & 0.92 & & 0.9 & \\
\hline
\end{tabular}

${ }^{1}$ Results of the ANCOVA test. $\mathrm{R}^{2}$ values were not reported for BF and BFPE as the lines were generated by two values.

\subsection{Clinical Samples}

The HPLC method was finally applied to routine clinical samples, including two BFPE high-grade serous ovarian cancer samples (B1 and B2), 10 FFPE tissues of different cancer types and three RNAs obtained from peripheral blood. Figure 7 shows examples of HPLC separation and the percentage of each of the canonical NMP is reported in Table 7.

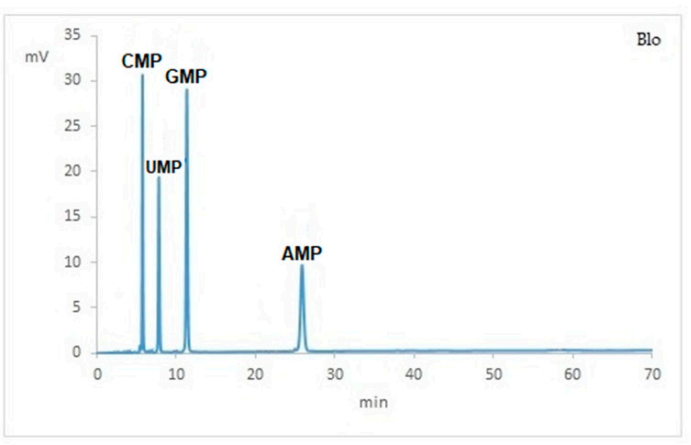

(a)

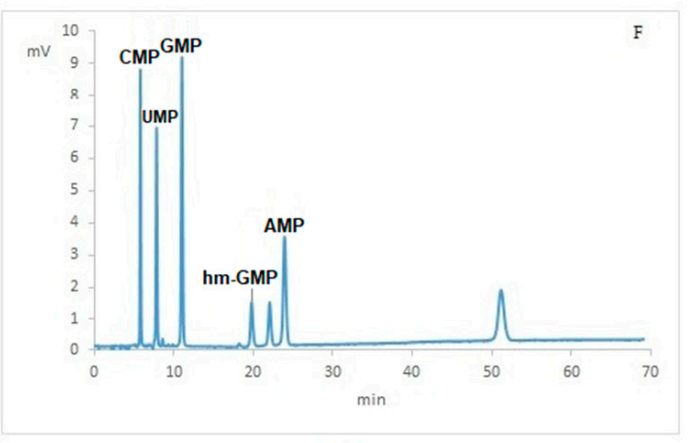

(b)

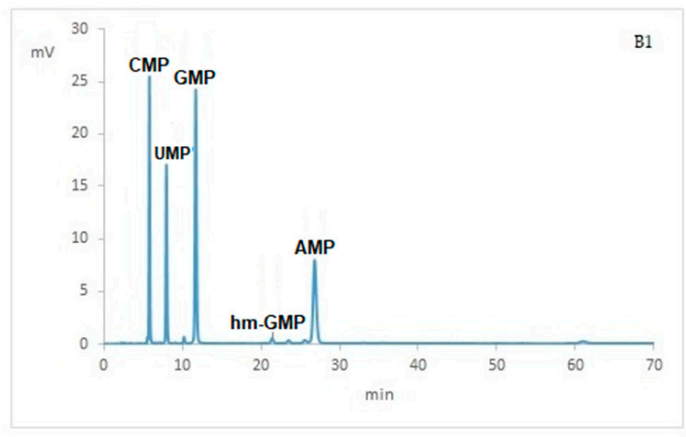

(c)

Figure 7. HPLC analysis of routine clinical samples: Chromatograms of (a) RNA from peripheral blood; (b) FFPE (ovarian cancer); (c) BFPE (ovarian cancer). Fixed and paraffin-embedded ovarian cancers display more complex patterns of digestion. 
Table 7. Results of HPLC analysis as area percentage of canonical NMPs and integrity of clinical samples. Samples' age is reported in years.

\begin{tabular}{ccccccccc}
\hline Sample & Sample & Age & RIN & CMP & UMP & GMP & AMP & TOT \\
\hline 1-HGSOC B1 & BFPE & 11 & 1.7 & $19 \%$ & $18 \%$ & $35 \%$ & $24 \%$ & $96 \%$ \\
2-HGSOC B2 & BFPE & 10 & 2.4 & $19 \%$ & $17 \%$ & $34 \%$ & $24 \%$ & $94 \%$ \\
3-HGSOC & FFPE & 9 & 2.3 & $12 \%$ & $15 \%$ & $23 \%$ & $18 \%$ & $63 \%$ \\
4-Breast 1 & FFPE & 30 & 2.4 & $16 \%$ & $17 \%$ & $31 \%$ & $24 \%$ & $88 \%$ \\
5-Breast 2 & FFPE & 28 & 2.4 & $22 \%$ & $17 \%$ & $33 \%$ & $25 \%$ & $97 \%$ \\
6-Colon 1 & FFPE & 20 & N.A. 1 & $19 \%$ & $16 \%$ & $32 \%$ & $22 \%$ & $89 \%$ \\
7-Colon 2 & FFPE & 18 & 2.0 & $22 \%$ & $17 \%$ & $33 \%$ & $23 \%$ & $95 \%$ \\
8-Glioma & FFPE & 11 & 2.2 & $18 \%$ & $15 \%$ & $34 \%$ & $25 \%$ & $92 \%$ \\
9-Melanoma & FFPE & 13 & 2.5 & $20 \%$ & $16 \%$ & $35 \%$ & $24 \%$ & $95 \%$ \\
10-Pancreas & FFPE & 15 & 2.4 & $20 \%$ & $14 \%$ & $36 \%$ & $19 \%$ & $89 \%$ \\
11-Prostate & FFPE & 18 & 2.3 & $19 \%$ & $17 \%$ & $35 \%$ & $26 \%$ & $97 \%$ \\
12-Uterine cervix & FFPE & 28 & 2.2 & $6 \%$ & $11 \%$ & $10 \%$ & $4 \%$ & $31 \%$ \\
13-Blood 1 & $\mathrm{Na}_{2}$ EDTA & 0 & 9.1 & $20 \%$ & $17 \%$ & $33 \%$ & $30 \%$ & $100 \%$ \\
14-Blood 2 & $\mathrm{Na}_{2}$ EDTA & 0 & 8.8 & $20 \%$ & $17 \%$ & $33 \%$ & $30 \%$ & $100 \%$ \\
15-Blood 3 & $\mathrm{Na}_{2}$ EDTA & 0 & 8.6 & $20 \%$ & $18 \%$ & $33 \%$ & $29 \%$ & $100 \%$ \\
Standard RNA & Solution & - & 9.7 & $22 \%$ & $17 \%$ & $34 \%$ & $27 \%$ & $100 \%$ \\
\hline
\end{tabular}

All the samples showed a reduced amount of the canonical NMP, down to $31 \%$ in a 28 -years old cervical uterine cancer. However, no relationship was found between the aging of the samples and the percentage of the canonical NMPs.

After the de-modification step (which was carried out at $80{ }^{\circ} \mathrm{C}$ for one hour in all fixed samples), only hm-GMP was detected in the chromatogram with different extent in all FFPE samples as well in BFPE samples. The ratio among peak areas (hm-GMP vs. GMP) was 0.02 in Bouin's sample 1, 0.03 in Bouin's sample 2, an up 0.28 in FFPE tissues. Furthermore, peaks at higher retention times ( $\geq 40 \mathrm{~min}$ ) were recorded in all the samples, with major amplitude in FFPE samples likely related to dimers (methylene di-adducts) between nitrogenous bases as resulting from the cross-linking process.

\subsection{RNA Quantification and Integrity of Clinical Samples}

The integrity of RNA extracts was investigated by the Agilent 2100 Bioanalyzer (Agilent Technologies; Santa Clara, CA, USA) recording the RIN number and quantifying the different RNA fragments. Gel-like images of the BioAnalayzer runs are available in the Supplementary Materials. Mean RIN number of fixed samples was 2.2 and the colon cancer 1 sample had non-assessable RIN value (Table 7).

In all fixed samples, the most representative fractions were related to fragments of 60-299 nucleotides as reported in Figure 8. In Bouin's fixed and embedded samples (1-2) the 60-149 nucleotides fragments were more represented than the 150-299 nucleotides fractions, while on average in formalin-fixed samples (3-12) the 150-299 nucleotides fraction prevailed. RNA from blood specimens had longer fragments as shown in Figure 8 (samples 13-15) and confirmed by the associated RIN numbers. 


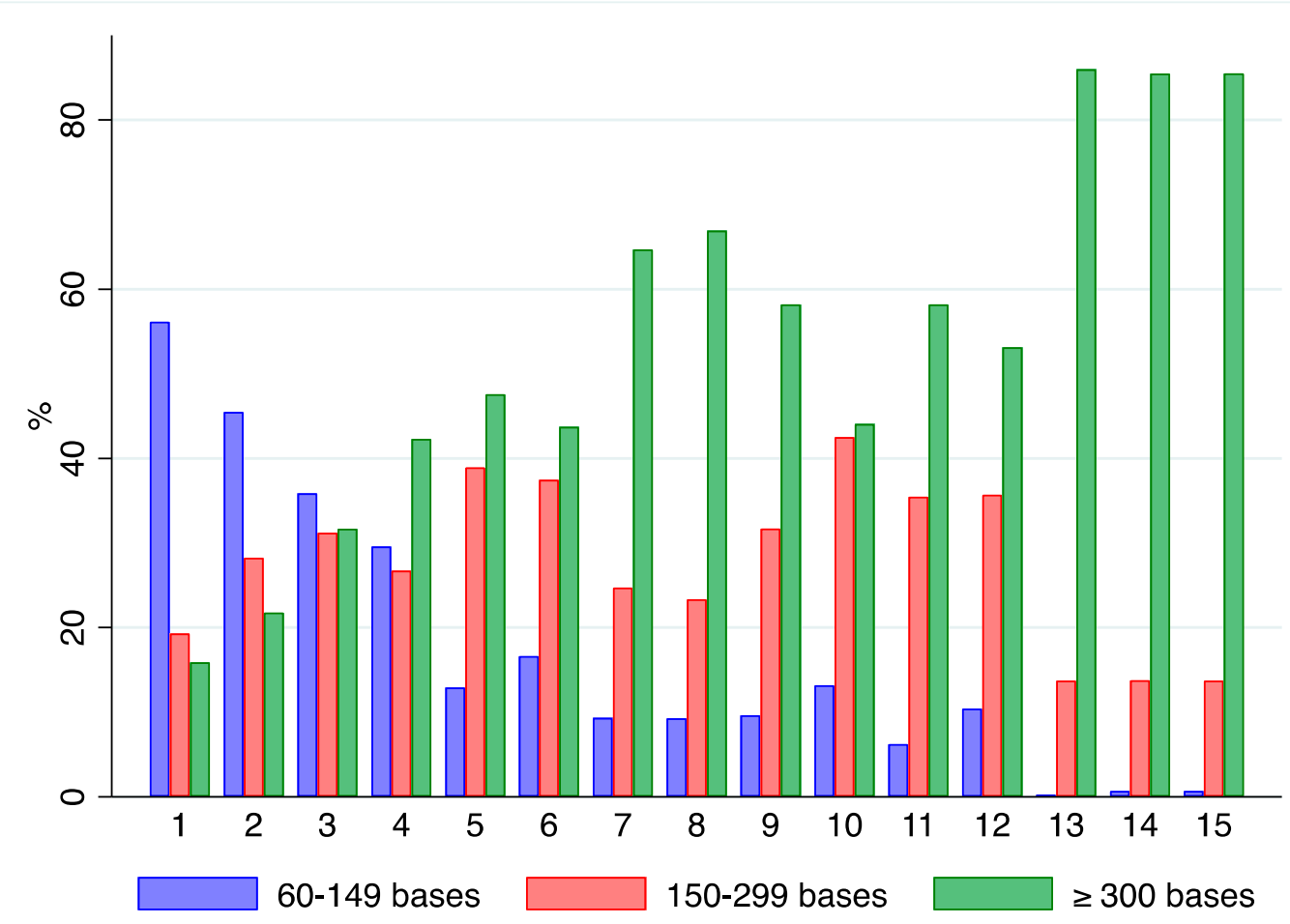

Figure 8. Analysis of RNA fragments length: Bar plots representing the distribution of 60-149 and 150-299 bases and equal to or over 300 bases fragments by BioAnalyzer method in clinical samples. Cases follow the order of Table 7: samples 1,2-BFPE samples; 3-12 FFPE samples; 13-15-Blood samples. BFPE samples show higher RNA degradation.

\section{Discussion}

Tissue fixation is a compulsory step for preserving cellular and tissue morphology for pathological examination. Fixation by itself introduces artifacts, involving some chemical modification of tissue components used to prevent their loss during tissue processing [19]. With respect to RNA preservation, it has already been reported that both formalin and alcohol-based fixatives have damaging effects on RNA preservation, and that the entity of those effects is fixative-specific [4]. In the present study, we propose a HPLC-based method as a tool to investigate on the RNA composition after fixation by analyzing the amount of canonical (e.g., unmodified) nucleotide monophosphates (NMP).

The method per se does not reveal the quality of RNA molecules in terms of fragment lengths, but rather it allows investigating the chemical integrity of each of the four canonical NMP of the RNA. The method in fact allows both identification and quantification of the NMPs released by the enzymatic digestion with nuclease S1 from as low as 600-700 ng of RNA. Consequently, in agreement with our expectation, only the four canonical NMPs were detected in our control samples. In addition, although non-quantifiable owing to the unavailability of commercial standards, home-synthesized hydroxymethyl NMPs (e.g., the most abundant classes of formaldehyde-deriving products) were efficiently resolved as well.

Out of the hm-NMPs, only hm-GMP was detected in our series of FFPE mouse liver samples as well as in clinical samples. Among hydroxymethyl nucleotide monophosphates, hm-AMP was reported to account around $40 \%$ of Adenines [7], but it was not identified at the expected retention time in our chromatograms. The fact that hm-NMPs have not been detected in our HPLC analyses is not surprising because our RNA isolation method has included a de-modification step at $80^{\circ} \mathrm{C}$. Several authors, have indeed claimed that heat-mediated de-modification of RNA from FFPE tissues mitigates the adverse effects of formalin on RNA [7,20,21], reporting that the de-modification step 
allows the removal of about $72.5 \%$ of modification, presumably methylol addition [7]. Furthermore, hydroxymethyl derivatives of dNMPs have been reported to be quite labile and unstable, therefore also for NMPs derivatives it is possible that their absence in the chromatograms could be related to their instability [22,23]. This hypothesis is supported also by our chromatograms without the de-modification step (Appendix C, Figure A4), where the hm-AMP and hm-CMP were not detectable. Regarding the rate of modification of NMPs, data in the literature are heterogeneous with the limitation that most studies analyzed DNA and reported data from in vitro reaction and not from ex vivo analysis. Masuda and co-workers found that Adenine and Cytosine were the most modified nitrogenous bases after in vitro treatment of RNA with formaldehyde [7], while Karmakar and colleagues focused their study mostly on AMP and dAMP [24]. Our results on the in vitro conversion of NMPs by formaldehyde rank AMP modification (66\%) above CMP (50\%) and GMP (36\%). In agreement with Masuda et al. UMP has not been modified by formaldehyde addition [7]. Our ranking of hm-AMP above hm-CMP and hm-GMP agrees with Beland who reported the same ranking for the hydroxymethyl-dNMPs. For DNA adducts, the order mirrors also their ease of formation and their relative stability [22]. The fact that we detected only hm-GMP is surprising and can find a possible explanation in the more complex reaction of formaldehyde with the derivatives of Guanine, with three potential sites of reaction (the two protons of the amino group at C-2, and the proton of the $\mathrm{N} 1$ nitrogen of the heterocyclic ring) [25]. Furthermore, our results showed that the de-modification step can reduce the hm-GMP peak of up to 10 times and it doesn't influence the RIN value by Agilent Bioanalyzer (see Appendix C, Figures A4 and A5).

In our series of mouse livers, differences were detected in the HPLC profile of formalin-fixed samples when compared to FFPE ones. Higher values of canonical NMPs were assessed in the former $(85 \%$ vs. $80 \%)$ and no peak referring to hm-GMP was detected as well. The latter result could have different explanations. From one side it is possible that the absence of the dehydration process in fixed sample and the subsequent treatment of the sample in aqueous phase for the RNA isolation allows the re-conversion of hm-GMP to GMP, as observed for hm-dAMP [25]. It is also possible that the dehydration process in alcohol may play a role in the conversion of formaldehyde-modified nucleic acids [26], which of course is lacking in pure formalin-fixed samples. Lastly, signals at higher retention times ( $>40 \mathrm{~min}$ ) in our chromatograms are likely due to bridging irreversible dimers of amino bases [24] between NMPs or between NMPs and protein residues. A confirmation of that interpretation is given by the presence of that peak only in FFPE liver. Methylene di-adducts are known to be more stable than the hm-NMPs explaining their detectability in both formalin-fixed and FFPE samples [22].

Both formalin and Bouin's solution are formaldehyde-based fixative, but different patterns of modification were found by HPLC analysis in mouse livers. The amount of unmodified NMP was always higher in Bouin's fixed samples when compared to formalin-fixed ones (96-100\% vs. $80-85 \%$ ) Bouin's fixative is made up of picric and acetic acids as coagulant components of the fixative and formaldehyde as cross-linking one [27]. RNA from BS fixed samples resulted more degraded in terms of fragment detection and RT-PCR analyses, indicating a possible ab initio fragmentation due to the low $\mathrm{pH}$ of the fixation solution $[2,6,27]$. The modification of nitrogenous bases in BS fixation is likely avoided or reduced by the acidic $\mathrm{pH}$ of the solution [28].

In our series of mouse livers, the quality of samples in terms of RT-PCR seems to be higher in fixed and paraffin-embedded specimens if compared to fixed ones, independently of the fixative used. That apparent discrepancy can find a possible explanation in fixed sample treatment, which were submitted to fixation, washed and frozen at $-80^{\circ} \mathrm{C}$. For RNA isolation, they were thawed and submitted to mechanical homogenization. The fact that fixed samples were not dehydrated, maintaining residual water in tissues and that a freezing/thawing cycle was applied together with the heating due to mechanical homogenization might account for that difference. This is further supported by the intrinsic properties of mt-CO1 gene (also known as ERR marker), which has been reported to be resistant to RNAse degradation, but heat-sensitive [15]. That marker had a higher $\Delta$ amp in fixed samples in comparison to their correspondent fixed and paraffin-embedded samples (Appendix B, Table A1). 
Given the same pre-analytical steps before fixation, our analyses on mouse tissues confirm that Bouin's fixative induces higher fragmentation of RNA, as shown by the absence of amplification of 302 bases stretches as well as by higher level of 60-149 fragments at the BioAnalyzer (Figure 5). Similarly, RCL2 ${ }^{\circledR}$ proved to preserve better RNA after fixation assuring about $99 \%$ of unmodified NMPs, while this value lowered to $88 \%$ after embedding procedure, likely due to the procedure itself [26]. By comparing regression lines for the different pre-analytical procedures in mouse livers, the slopes of the lines were almost similar among treatments, differing only for BFPE livers. This indicates that the efficiencies of PCR systems did not vary among treatments; ergo no particular inhibitory effects were recorded for most of them, but BFPE. The different values of intercepts are indicative of the different starting conditions, namely the sample degradation level due to the fixatives, among pre-analytical processes.

The HPLC method was also applied to a set of aged clinical samples (see Table 7), which showed some differences when compared to mouse livers. Although to a minor extent, hm-GMP signal and peaks at retention times $\geq 40$ min were found also in Bouin's fixed paraffin-embedded ovarian cancer samples (Figure 7c). This might be due to the pre-analytical conditions at the time of tissue collection accounting for minor composition differences of BS that could have allowed the cross-linking activity of formaldehyde in clinical Bouin's samples. Furthermore, for mouse livers ISO pre-analytical standard was applied for tissue collection and processing [14] in order to guarantee an optimal quality level in the samples. Nevertheless, tissue embedding was also reported to induce transcriptional artifacts [21,26]. Another concurrent phenomenon is related to tissue storage period in the archive, which is known to influence the quality of nucleic acids from fixed tissues [29-33]. Similarly, differences in terms of hm-GMP amount observed between routine clinical FFPE samples can be ascribed mainly to the diverse pre-analytical procedures.

In conclusion, the HPLC method here described makes it possible to detect the four canonical NMPs of the RNA as well as their hydroxymethyl derivatives. Most importantly, when applied to less than $1 \mu \mathrm{g}$ of RNA from fixed tissues, it provides valuable data on chemical modification of RNA molecule as produced by fixation processes. It has been possible to demonstrate, indeed, that RCL $2^{\circledR}$, as possibly most alcohol-based fixatives, does not induce chemical modification of the nucleotide monophosphates. In addition, our data support that Bouin's solution prevents, in ISO standard pre-fixation conditions, the cross-linking activity of formaldehyde. Furthermore, we have shown that $\mathrm{hm}$-GMP is the most represented hm-NMP. We acknowledge as a limitation of this method that it allows the quantification on unmodified NMPs as indirect proof on the non-modification of RNAs, without any additional information on the degradation of the transcripts, which is mandatory for further molecular analysis. Nevertheless, the presented method could easily be applied for analyzing the effect of novel fixatives and/or RNA de-modification procedures. Consequently, these data on the molecular composition of the template, coupled to conventional and newly proposed methods, such as the PERM and DV algorithm from BioAnalyzer for assessing the molecular weight of the templates, are helpful in the evaluation of RT-qPCR- based results that can be achieved from archived fixed and paraffin-embedded samples. Even in long-term stored FFPE tissues, only hm-GMP and di-adducts were found after the de-modification step of the RNA, without correlation with the age of the blocks. The present results stress that pre-analytical procedures play a major role in the quality of the clinical specimens, thus confirming that the use of the ISO standard document [14] guarantees higher quality level samples for molecular investigations.

\section{Materials and Methods}

\subsection{RNA Digestion}

Hydrolysis of the nucleic acids was achieved by enzymatic reactions which cleave the RNA molecule to $5^{\prime}$-mono-nucleotide. Three different enzymes were tested: S1 Nuclease (Promega, Madison, WI 53711-5399, USA; Cat. No. E567B), S1 Nuclease (Invitrogen- Thermo Fischer Scientific, Waltham, MA 02451, USA; Cat. No. 180001-016) and RNAase ONE ${ }^{\mathrm{TM}}$ Ribunclease (Promega, Madison, 
WI 53711-5399, USA; Cat. No. M426A). For assessing the digestion conditions, $5 \mu \mathrm{g}$ of each 15 bases oligo (polyA, polyC, polyG and polyU, purchased by IDT-Integrated DNA Technologies; Leuven, Belgium) as well $5 \mu \mathrm{g}$ of a control RNA purchased by Celbio were incubated in $1 \times$ working buffer with 50-160 units of enzyme at $37^{\circ} \mathrm{C}$ for two hours in a final volume of $50 \mu \mathrm{L}$. After digestion, the samples were immediately stored at $-20^{\circ} \mathrm{C}$ up to HPLC analysis. The following digestion reactions of mouse liver as well as clinical samples were carried out using about $2 \mu \mathrm{g}$ of RNA with 80 units of S1 Nuclease (Promega, Madison, WI 53711-5399, USA) in the abovementioned conditions.

\subsection{Fixation Procedure}

Four wild type Black Swiss mouse livers were collected at the ICGEB animal house after sacrifice. Each liver was washed in PBS, blotted onto a paper and immediately chilled on wet ice for transport. At the pathology department, livers were subdivided into fragments and submitted to fixation. Each liver tissue was equally represented in the different treatments. According to ISO standard [14] a duplicate of samples for each treatment were fixed for $24 \mathrm{~h}$ in neutral buffered formalin, Bouin's solution and RCL-2 at room temperature in the dark. Afterwards, fixed samples were washed in PBS and a set of samples for each treatment was blotted onto paper and stored at $-80^{\circ} \mathrm{C}$ up to RNA isolation. The second set of samples was dehydrated and paraffin-embedded following standard procedures [14]. A replicate of fixed samples was obtained during this procedure. Thus, in total, 12 samples (fixed + fixed and paraffin-embedded) were processed for this study.

\subsection{HPLC Analysis}

HPLC analyses were run on a non-thermostated Agilent series 1100 liquid chromatograph equipped with a Kinetex C18 $250 \times 4.6 \mathrm{~mm} 5 \mu \mathrm{m} 100 \AA$ A (Phenomenex, Torrance, CA 90501-1430, USA) column with a column guard, a $20 \mu \mathrm{L}$ loop and a UV detector at $260 \mathrm{~nm}$. The flow was set to $1 \mathrm{~mL} / \mathrm{min}$. The eluent was phosphate buffer $0.03 \mathrm{M}(\mathrm{pH} 7.4)+$ tetrabutylammonium hydroxide (TBAH) $10 \mathrm{mM}$. For $1 \mathrm{~L}$ phosphate buffer in water (mQ): $3.53 \mathrm{~g}\left(\mathrm{NH}_{4}\right)_{2} \mathrm{HPO}_{4}+0.76 \mathrm{~g}\left(\mathrm{NH}_{4}\right) \mathrm{H}_{2} \mathrm{PO}_{4}$ $+2.6 \mathrm{~mL}$ of $40 \%$ TBAH solution were mixed in water. The phosphate buffer was filtered through a $500 \mathrm{~mL}$ Nalgene ${ }^{\mathrm{TM}}$ Rapid-Flow $^{\mathrm{TM}}$ Sterile Disposable Filter Unit with PES $0.2 \mu \mathrm{M}$ membrane prior to use. To quantify unmodified nucleotides monophosphate 1a-4a (Figure A1), sodium salts of NMPs were purchased by Millipore-Sigma Italy. Calibration curves were obtained using scalar solutions of each one (Adenosine $5^{\prime}$-monophosphate disodium salt 1a. Guanosine $5^{\prime}$ - monophosphate disodium salt 2a. Cytidine $5^{\prime}$-monophosphate disodium salt 3a; Uridine $5^{\prime}$ - monophosphate disodium salt 4a) in the range of concentration $0.00026-0.14 \mu \mathrm{g} / \mu \mathrm{L}$. Calibration curve of all mononucleotides $1 \mathrm{a}-4 \mathrm{a}$ showed a good response linearity with a coefficient of correlation $\left(R^{2}\right)$ of 0.999 . Fixed samples were spiked with each nucleotide-monophosphate-disodium salt to definitely identify the unmodified 1a-4a nucleotide peaks in HPLC analysis. Fixed samples were diluted 1:10 in phosphate buffer and injected in HPLC in triplicate analyses for a run time of 60-70 min.

Each HPLC analysis was carried out loading about $600-700 \mathrm{ng}$ of digested material.

\subsection{RNA Isolation}

\subsubsection{RNA Isolation from Fixed Specimens}

On average $35 \mathrm{mg}$ of formalin, Bouin and RCL2 fixed tissues were cut on a cold surface and transferred into a cleaned $2 \mathrm{~mL}$ vial. The homogenization was performed with $50 \mu \mathrm{l}$ of Lysis solution obtained by the Maxwell ${ }^{\circledR}$ RSC RNA FFPE kit (Cat. No. AS1440; Promega, Madison, WI, USA) using a homogenizer (Ultra-Turrax T25 basic. IKA ${ }^{\circledR}$-WERKE; Staufen, Germany). The homogenization was carried out in wet ice for $20 \mathrm{~s}$ for four times at 20,000 rpm. Successively, $200 \mu \mathrm{L}$ of Lysis solution and $15 \mu \mathrm{L}$ of proteinase $\mathrm{K}$ were added to the homogenized samples and processed following the instructions of Maxwell ${ }^{\circledR}$ RSC RNA FFPE kit (Cat. No. AS1440). Total RNA was automatically eluted in $50 \mu \mathrm{L}$ of Nuclease-free water, split into aliquots and stored at $-80^{\circ} \mathrm{C}$. RNA concentration and purity 
were measured by absorbance through NanoDrop ${ }^{\mathrm{TM}}$ ND-1000 spectrophotometer (Thermo Fischer Scientific; Waltham, MA, USA).

\subsubsection{RNA Isolation from Fixed and Paraffin-Embedded Specimens}

RNA was isolated from fixed and paraffin-embedded mouse liver samples and from routine clinical tissues. With regards of clinical tissues, two Bouin's fixed and paraffin-embedded high-grade ovarian cancer samples and ten cancer FFPE samples of different origin were used. Those specimens were collected at the National Cancer Institute of Aviano and at the University Hospital of Trieste. Informed consent was obtained from participants included in the study and ethical approval was obtained by the Institutional Review Board of CRO-Aviano (protocol number 1213, 24 January 2017) and by the ethical committee of the University of Trieste (report n. 17, 4 August 2008).

RNA was isolated from four $10 \mu \mathrm{m}$-thick sections of fixed and paraffin-embedded specimens using the Maxwell ${ }^{\circledR}$ RSC instrument (Promega; Madison, WI, USA) following the instruction of the Maxwell ${ }^{\circledR}$ RSC RNA FFPE kit (Cat. No. AS1440). The protocol of isolation includes a digestion step at $56^{\circ} \mathrm{C}$ and a de-modification step of $1 \mathrm{~h}$ at $80^{\circ} \mathrm{C}$. After RNA isolation, samples were split into aliquots and stored at $-80^{\circ} \mathrm{C}$. RNA quantification and purity detection were assessed by NanoDrop ${ }^{\mathrm{TM}}$ ND-1000 spectrophotometer (Thermo Fischer Scientific; Waltham, MA, USA).

\subsubsection{RNA Isolation from Peripheral Blood}

RNA was isolated from peripheral blood from healthy volunteers by the use of Tri-reagent (Cat. No T9424, Millipore-Sigma, Milano, Italy). Samples were split into aliquots and stored at $-80{ }^{\circ} \mathrm{C}$. RNA quantification and purity detection were assessed by NanoDrop ${ }^{\mathrm{TM}}$ ND-1000 spectrophotometer (Thermo Fischer Scientific, Waltham, MA, USA). Afterwards, an aliquot of RNA was submitted to DNAse digestion.

\subsection{DNase Digestion}

Thirty $\mu \mathrm{L}$ of total RNA were treated with $20 \mathrm{U}$ of DNase I (Cat. No. 04716728001; Roche. Mannheim, Germany) and 20 U of RNase Inhibitor (Cat. No. N8080119; Thermo Fisher Scientific. Waltham, MA, USA) at $25^{\circ} \mathrm{C}$ for $20 \mathrm{~min}$. Then the reaction was stopped with $4 \mu \mathrm{L}$ of EDTA $25 \mathrm{mM}$ at $65^{\circ} \mathrm{C}$ for $10 \mathrm{~min}$ as already described [34]. Samples were split into aliquots and stored at $-80^{\circ} \mathrm{C}$.

\subsection{RNA Integrity}

RNA integrity was assessed through automated electrophoresis by the Agilent 2100 Bioanalyzer instrument (Agilent Technologies; Santa Clara, CA, USA). One microliter of each sample was loaded into the sample well of the Agilent RNA 6000 Nano Chip (Cat. No. 5067-1529; Agilent Technologies; Santa Clara, CA, USA) which was previously filled with the gel-dye mixture and the $5 \mu \mathrm{L}$ of RNA 6000 Nano Marker, as suggested by the manufacture's instruction (Cat. No. 5067-1512; Agilent Technologies; Santa Clara, CA, USA). In addition, the distribution of different length fragments was measured by the relative abundance in comparison to the total RNA area. The five ranges were defined as follows: from 1 to 59 nucleotides (1), from 60 to 149 (2), from 150 to 299 (3), from 300 to 449 (4) and equal or over 450 (5).

\subsection{Reverse Transcription and Real-Time PCR Assay}

For mt-CO1gene amplification $200 \mathrm{ng}$ of mouse RNA were reverse transcribed using $250 \mathrm{U}$ M-MLV reverse transcriptase (Thermo Fischer Scientific, Waltham, MA, USA; Cat. No. 28025013), 1 mM dNTPs, $0.01 \mathrm{M}$ DTT, $4.5 \mathrm{mM} \mathrm{MgCl} 2$ and $8 \mathrm{U}$ RNase Inhibitors (Thermo Fischer Scientific, Waltham, MA, USA; Cat. No. E00382) as already reported [35]. The amplification reactions for the mouse mitochondrially encoded cytochrome c oxidase I (mt-CO1) gene (mt-CO1) consist of three individual qPCR analyses amplifying fragments of 60 (S-Small fragment), 179 (M-Medium fragment) and 302 bases (L-Long 
fragment) using already published primer sequences [18]. For each real-time PCR reaction, $20 \mathrm{ng}$ of cDNA was added to $10 \mu \mathrm{L}$ of Fast EvaGreen qPCR Master Mix $2 \times$ (Biotium, Fremont, CA, USA; Cat. No. 31003), $300 \mathrm{nM}$ of reverse and forward primers (IDT, Coraville, IA, USA) in a final volume of $20 \mu \mathrm{L}$. Each reaction was run in duplicate on a Mastercycler ${ }^{\circledR}$ ep Realplex (Eppendorf, Hamburg, Germany) using the following cycling conditions: $95^{\circ} \mathrm{C}$ for $2 \mathrm{~min}, 45$ cycles of $95^{\circ} \mathrm{C}$ for $20 \mathrm{~s}, 30 \mathrm{~s}$ of annealing temperature and the extension at $72{ }^{\circ} \mathrm{C}$ for 30 or $45 \mathrm{~s}$ (extension time of $45 \mathrm{~s}$ was used for 302 bases amplicon). Annealing temperature was $60^{\circ} \mathrm{C}$ for 60 bases amplicon, $57.5^{\circ} \mathrm{C}$ for 179 bases amplicon and $61^{\circ} \mathrm{C}$ for 302 bases amplicon. At the end of the protocol, the melting curve analysis was carried out to evaluate the specificity of the amplified products.

\section{8. $\triangle$ Amp Analysis}

The $\Delta$ Amp method [15] was applied to measure the difference in threshold cycles between amplicons of the mt-CO1 gene. According to the published method differences were calculated between threshold cycles related to the amplification of mt-CO1 M (179 bases) and S (60 bases) and between $\mathrm{L}$ amplicon (302 bases) $\mathrm{S}$ ( 60 bases). The method is based on mt-CO1 gene amplification, which is virtually resistant to RNases [15], therefore it can be used to monitor the chemical and physical degradation of RNAs.

\subsection{Statistical Analysis}

Linear regression was performed by plotting the $\mathrm{Ct}$ values versus the amplicon size for each pre-analytical condition. ANCOVA test was run to investigate on regression lines, in detail to test if slopes and intercepts were significantly different. Bonferroni analysis was carried out to inspect multiple comparison among all samples. All the statistical analyses were carried out using the GraphPad Prism 8.0 software (San Diego, CA, USA).

Supplementary Materials: Supplementary materials can be found at http://www.mdpi.com/1422-0067/21/20/7540/s1. Figure S1 Gel-like images of the BioAnalayzer runs of (a) 1-ladder and mouse livers submitted to different treatment: 2-Fresh frozen; 3-24 h in neutral buffered formalin (FF); $4-24 \mathrm{~h}$ in neutral buffered formalin and paraffin embedded (FFPE); $5-24 \mathrm{~h}$ in Bouin's solution (BF); 6-24 h in Bouin's solution and paraffin embedded (BFPE); 7-24 h in RCL2 (RF); 8-24 h in RCL2 and paraffin embedded (RFPE); (b) 1—ladder; and clinical samples 2-HGSOC B1; 3-HGSOC B2; 4-HGSOC; 5-Breast 1 and 6-Breast 2; (c) 1-ladder; and clinical samples 2-Colon 1; 3-Colon 2; 4-Blood 1; 5-Blood 2; (d) 1-ladder; and clinical samples 2-Glioma; 3-Melanoma; 4-Pancreas; 5-Prostate; 6-Uteral Cervix and 7-Blood 3. RIN values are reported in Tables 5 and 7 of the main document.

Author Contributions: Conceptualization. S.B. and P.F.; formal analysis. S.B., C.F., P.F., E.D.M., D.T., E.A.; clinical sample acquisition V.C. and G.S.; investigation. S.B., G.S., and P.F.; data curation. D.T., C.F., E.A. and E.D.M.; methodology S.B., P.F.; writing—original draft preparation. S.B., C.F., P.F., E.D.M., D.T.; writing-review and editing. S.B., C.F., P.F., V.C. and G.S.; funding acquisition, G.S. and S.B. All authors have read and agreed to the published version of the manuscript.

Funding: This research was partially funded by MIUR PRIN 2015, protocol number 2015HAJH8E_002. The publication of this article was supported by the project SPIDIA4P funded by the European Union's Horizon 2020 research and innovation program under grant agreement No 733112.

Acknowledgments: The authors are grateful to Serena Zacchigna (University of Trieste and ICGEB) and Willy De Mattia from the ICGEB-International Centre for Genetic Engineering and Biotechnology of Trieste, for providing the mouse livers for experiments. The authors are grateful to the FP7 project SPIDIA (contract no. 222916), the H2020 project SPIDIA4P (contract no. 733112), for the efforts made to create technical documents and standards for pre-analytical conditions for tissue processing useful for in vitro diagnostics. The publication of this article was supported by the project SPIDIA4P funded by the European Union's Horizon 2020 research and innovation program under grant agreement No 733112. The authors would like to thank the MIUR for supporting this research through the research project number 2015HAJH8E_002 (PRIN 2015).

Conflicts of Interest: The authors declare no conflict of interest. 


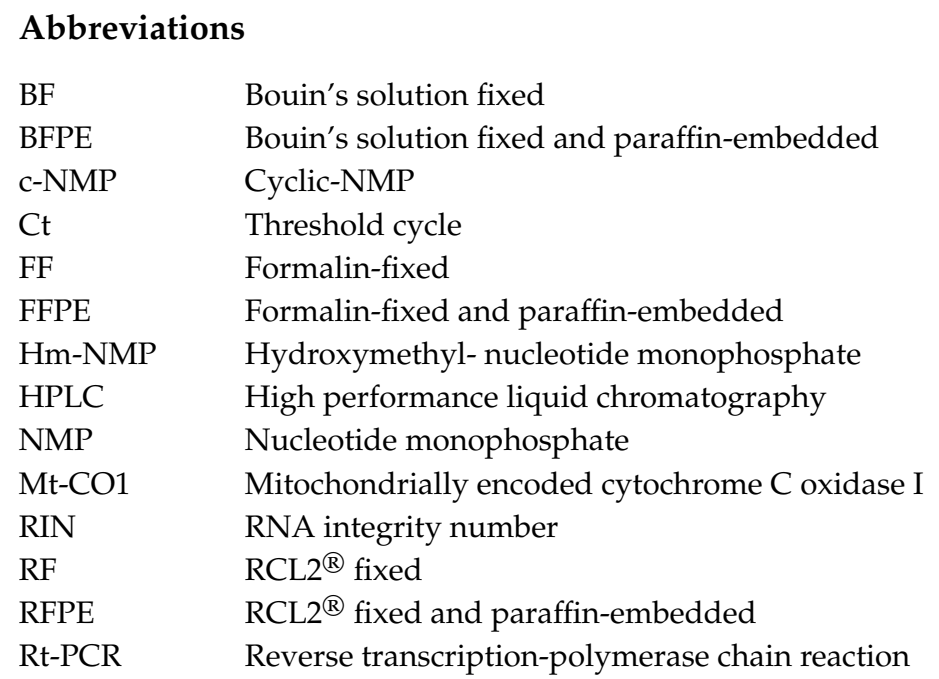

\section{Appendix A}

The main step in formalin fixation process is the formation of hydroxymethyl adducts to nitrogenous bases. Hydroxymethyl-AMP, -CMP, -UMP and -GMP are not commercially available, therefore they were synthesized in vitro. The main target was to verify that those species do not overlap with unmodified nucleotides monophosphate in HPLC analysis. Consequently, the synthesis and characterization of those hydroxymethyl adducts is reported here below.

\section{Appendix A.1. Synthesis of Hydroxymethyl-AMP, -CMP, -UMP and -GMP}

Synthesis was carried out as already described [26]. Briefly, $10 \mathrm{~mL}$ of $20 \mathrm{mM}$ solution of each nucleotide-monophosphate- disodium salt in $4 \%$ neutral buffered formaldehyde was generated and left for 1 week at room temperature in dark. The crude mixtures referring to the 4 reactions were precipitated from ice cold $2 \% \mathrm{LiClO}_{4}$ in acetone and centrifuged for $15 \mathrm{~min}$ at $1000 \times \mathrm{g}$ at $4{ }^{\circ} \mathrm{C}$. The supernatant liquid was discarded and the precipitates were washed twice with ice-cold acetone. The crude mixture was evaporated to dryness under vacuum and stored at $-20{ }^{\circ} \mathrm{C}$ up to HPLC and ${ }^{1} \mathrm{H}-\mathrm{NMR}$ analysis.

\section{Appendix A.2. 1H-NMR Characterization of Hydroxymethyl-AMP, -CMP, -UMP and-GMP}

${ }^{1} \mathrm{H}-\mathrm{NMR}$ spectra were recorded on a Varian 400-MR spectrometer using $\mathrm{D}_{2} \mathrm{O}$ as solvent (calibration was set on $\mathrm{H}_{2} \mathrm{O}$ signal at $4.65 \mathrm{ppm}$ ). Coupling constants (J) are given in Hz. Analysis of the NMR spectra was performed using the MestReNova NMR data processing of Mestrelab Research S.L. ${ }^{1} \mathrm{H}-\mathrm{NMR}$ spectra are related to the structures reported in Figure A1.

AMP 1a (sodium salt) ${ }^{1} \mathrm{H}$ NMR $\left(400 \mathrm{MHz}, \mathrm{D}_{2} \mathrm{O}\right),(\mathrm{ppm}): 3.97\left(\mathrm{~m}, \mathrm{H}-5^{\prime}\right), 4.24\left(\mathrm{~m}, \mathrm{H}-4^{\prime}\right), 4.36$ (dd, $\mathrm{J}_{1}$ 3.7, $\mathrm{J}_{2}$ 5.1, $\left.\mathrm{H}-3^{\prime}\right), 5.98\left(\mathrm{~d}, \mathrm{~J} 5.8, \mathrm{H}^{-1}{ }^{\prime}\right), 8.08(\mathrm{~s}, \mathrm{H}-8), 8.34(\mathrm{~s}, \mathrm{H}-2)$. Chemical shifts are in accordance with the literature [9].

Hm-AMP $1 \mathbf{b}$ in admixture with $\mathbf{1 a}(66 \%$ of $\mathbf{1 b}){ }^{1} \mathrm{H}$ NMR $\left(400 \mathrm{MHz}, \mathrm{D}_{2} \mathrm{O}\right), \delta(\mathrm{ppm}): 3.86\left(\mathrm{~m}, \mathrm{H}-5^{\prime}, \mathbf{1 a}+\mathbf{1 b}\right)$, $4.21\left(\mathrm{~m}, \mathrm{H}-4^{\prime}, \mathbf{1 a}+\mathbf{1 b}\right), 4.36\left(\mathrm{~m}, \mathrm{H}-3^{\prime}, \mathbf{1 a}+\mathbf{1 b}\right), 5.01\left(\mathrm{~s}, \mathrm{NHCH}_{2} \mathrm{OH}, \mathbf{1 b}\right), 5.98$ (d, J 5.8, H-1', $\left.\mathbf{1 a}\right), 6.00$ (d, J 5.9, H-1', 1b), 8.09 (s, H-8, 1a), 8.19 (s, H-8, 1b), 8.45 (s, H-2, 1a), $8.48(\mathrm{~s}, \mathrm{H}-2,1 \mathbf{b})$.

GMP 2a (sodium salt) ${ }^{1} \mathrm{H}$ NMR (400 MHz, $\left.\mathrm{D}_{2} \mathrm{O}\right),(\mathrm{ppm}): 3.85\left(\mathrm{~m}, \mathrm{H}-5^{\prime}\right), 4.18\left(\mathrm{~m}, \mathrm{H}-4^{\prime}\right), 4.33\left(\mathrm{~m}, \mathrm{H}-3^{\prime}\right), 5.76(\mathrm{~d}$, J 5.8, H-1'), 8.05 (s, H-8).

Hm-GMP $2 \mathbf{b}$ in admixture with $\mathbf{2 a}(36 \%$ of $\mathbf{2 b}){ }^{1} \mathrm{H}$ NMR $\left(400 \mathrm{MHz}, \mathrm{D}_{2} \mathrm{O}\right),(\mathrm{ppm}): 3.86\left(\mathrm{~m}, \mathrm{H}-5^{\prime}, \mathbf{2 a}+\mathbf{2 b}\right)$, $4.21\left(\mathrm{~m}, \mathrm{H}-4^{\prime}, \mathbf{2 a}+\mathbf{2 b}\right), 4.36\left(\mathrm{~m}, \mathrm{H}-3^{\prime}, \mathbf{2 a}+\mathbf{2 b}\right), 4.79$ (apparent d, J 4.4, NHC$\left.\underline{H}_{2} \mathrm{OH}, 2 \mathbf{b}\right), 5.75\left(\mathrm{~d}, \mathrm{~J} 6.0, \mathrm{H}-1^{\prime}, 2 \mathbf{2 a}\right)$, $5.88\left(\mathrm{~d}, \mathrm{~J} 5.9, \mathrm{H}-\mathrm{1}^{\prime}, \mathbf{2 b}\right), 8.03$ (s, H-8, 2a), 8.04 (s, H-8, 2b).

CMP 3a (sodium salt) ${ }^{1} \mathrm{H}$ NMR (400 MHz, $\mathrm{D}_{2} \mathrm{O}$ ), (ppm): 3.83 (ddd, $\mathrm{J}_{1} 11.9, \mathrm{~J}_{2}$ 5.0, J3 2.9, H-5'), 3.91 (ddd, $\left.\mathrm{J}_{1} 11.9, \mathrm{~J}_{2} 3.7, \mathrm{~J}_{3} 2.9, \mathrm{H}^{-} 5^{\prime}\right), 4.10\left(\mathrm{~m}, \mathrm{H}-4^{\prime}\right), 4.21\left(\mathrm{~m}, \mathrm{H}-3^{\prime}+\mathrm{H}-2^{\prime}\right), 5.87\left(\mathrm{~d}, \mathrm{~J} 3.9, \mathrm{H}-1^{\prime}\right), 6.00$ (d, J 7.6, H-5), 7.98 (d, J 7.6, H-6).

Hm-CMP $3 \mathbf{b}$ in admixture with $3 \mathbf{a}(50 \%$ of $\mathbf{3 b}){ }^{1} \mathrm{H}$ NMR $\left(400 \mathrm{MHz}, \mathrm{D}_{2} \mathrm{O}\right),(\mathrm{ppm}): 3.83\left(\mathrm{~m}, \mathrm{H}-5^{\prime}, \mathbf{3 a}+\mathbf{3 b}\right)$, $3.91\left(\mathrm{~m}, \mathrm{H}-5^{\prime}, 3 \mathbf{a}+3 \mathbf{b}\right), 4.09\left(\mathrm{~m}, \mathrm{H}-4^{\prime}, \mathbf{3 a}+3 \mathbf{b}\right), 4.18\left(\mathrm{~m}, \mathrm{H}-3^{\prime}+\mathrm{H}-2^{\prime}, 3 \mathbf{3}+\mathbf{3 b}\right), 5.84\left(\mathrm{~m}, \mathrm{H}-1^{\prime}, 3 \mathbf{a}+3 \mathbf{b}\right), 4.74(\mathrm{~s}$, $\left.\mathrm{NHCH}_{2} \mathrm{OH}, 3 \mathbf{b}\right), 5.96$ (d, J 7.6, H-5, 3b), 5.97 (d, J 7.6, H-5, 3a), 7.92 (d, J 7.6, H-6, 3a), 7.94 (d, J 7.6, H-6, 3b).

UMP 4a (sodium salt) ${ }^{1} \mathrm{H}$ NMR $\left(400 \mathrm{MHz}, \mathrm{D}_{2} \mathrm{O}\right),(\mathrm{ppm}): 3.82\left(\mathrm{ddd}, \mathrm{J}_{1} 11.8, \mathrm{~J}_{2}\right.$ 5.0, $\mathrm{J}_{3}$ 3.0, $\left.\mathrm{H}-5^{\prime}\right), 3.88$ (ddd, $\mathrm{J}_{1}$ 11.8, $\mathrm{J}_{2}$ 3.7, $\mathrm{J}_{3}$ 3.0, H-5'), 4.11 (m, H-4' ), 4.21 (t, J 4.2, H-3'), 4.28 (t, J 5.2, H-2'), 5.84 (d, J 8.1, H-5), 5.85 (d, J 5.2, H-1'), 7.98 (d, J 8.1, H-6).

As observed by their ${ }^{1} \mathrm{H}-\mathrm{NMR}$ spectra, $\mathbf{1 b}-\mathbf{3 b}$ showed a characteristic peak at $5.01 \mathrm{ppm}, 4.79 \mathrm{ppm}$ and $4.74 \mathrm{ppm}$ respectively, corresponding to the $\mathrm{CH}_{2}$ protons of the $\mathrm{NHCH}_{2} \mathrm{OH}$ group obtained after reaction with formaldehyde. The formylation reaction was in any event, not complete and a mixture of both unmodified 1a-3a and their corresponding hydroxylmethyl derivatives $\mathbf{1 b}-\mathbf{3 b}$ was obtained. Chemical shifts of all protons were 
different in all cases although overlapping was observed in some cases. To estimate the percentage of formylation for AMP the area of the H-8 signal of $1 \mathrm{a}(8.45 \mathrm{ppm})$ and $\mathbf{1 b}(8.48 \mathrm{ppm})$ was correlated giving $66 \%$ in favor of $1 \mathrm{~b}$. For GMP we referred to $\mathrm{H}_{-1} \mathbf{1}^{\prime}$ signal since they were well separated in the two compounds (5.75 ppm for $\mathbf{2 a}$ and $5.88 \mathrm{ppm}$ for $\mathbf{2 b}$ ) giving a conversion of $36 \%$ for compound $\mathbf{2 b}$. For CMP we referred to the hydroxymethyl signal of $\mathbf{3 b}$ and the H-1' signal which is the sum of both $\mathbf{3 a}$ and $\mathbf{3 b}$ giving a conversion of $50 \%$. In the case of UMP no signal appeared in the range $4.70-5.50 \mathrm{ppm}$ indicating that no formylation occurred. To confirm, all the other signals were not split as no hydroxymethyl derivative was formed. This is in accordance with the structure of UMP which hasn't got any amino group, while 1a-3a have an amino group in the heterocyclic ring which can react with formaldehyde.<smiles>Nc1ncnc2c1ncn2[C@@H]1O[C@H](COP(=O)([O-])[O-])[C@@H](O)[C@@H]1O</smiles>

1a: AMP<smiles>Nc1nc2c(ncn2C2OC(COP(=O)([O-])[O-])C(O)C2O)c(=O)[nH]1</smiles>

2a: GMP<smiles>Nc1ccn(C2OC(COP(=O)([O-])[O-])C(O)C2O)c(=O)n1</smiles>

3a: CMP<smiles>O=c1ccn(C2OC(COP(=O)([O-])[O-])C(O)C2O)c(=O)[nH]1</smiles><smiles>O=P([O-])([O-])OCC1OC(n2cnc3c(NCO)ncnc32)C(O)C1O</smiles>

1b: Hm-AMP<smiles>O=c1[nH]c(NCO)nc2c1ncn2C1OC(COP(=O)([O-])O)C(O)C1O</smiles>

2b: Hm-GMP<smiles>O=c1nc(NCO)ccn1C1OC(COP(=O)([O-])[O-])C(O)C1O</smiles>

3b: Hm-CMP

4a: UMP

Figure A1. Structure of mononucleotides $\mathbf{1 a}-\mathbf{4 a}$ and hydroxymethyl adducts $\mathbf{1} \mathbf{b}-\mathbf{3 b}$.

\section{Appendix A.3. HPLC Characterization of Hydroxymethyl-AMP, -CMP, -UMP and-GMP}

The crude mixtures of hydroxymethyl-nucleotide were dissolved in phosphate buffer and injected in HPLC as triplicate analysis (Figure A2). 


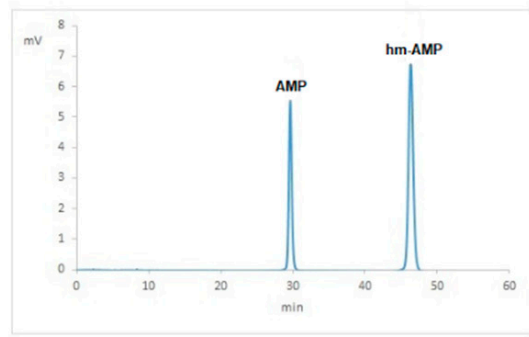

(a)

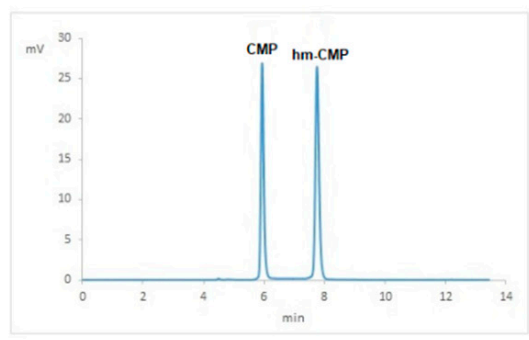

(c)
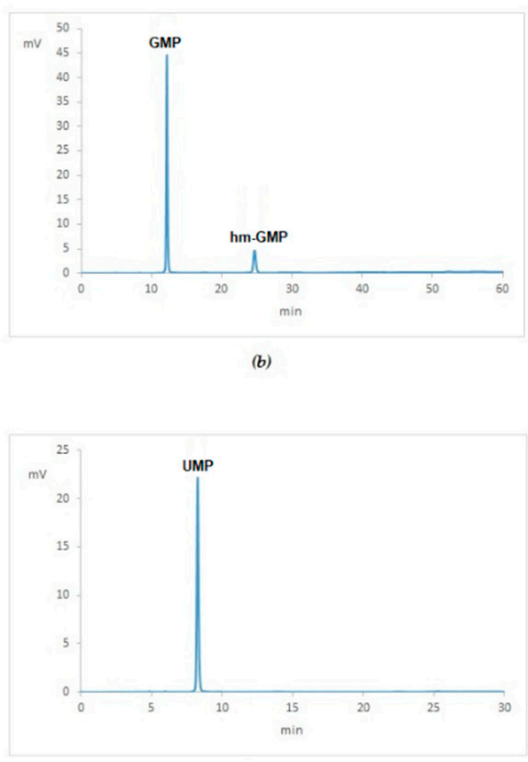

(d)

Figure A2. Chromatogram of: (a) hydroxymethyl-AMP 1b (peak 2) and unmodified AMP 1a (peak 1); (b) hydroxymethyl-GMP 2b (peak 2) and unmodified GMP 2a (peak 1); (c) hydroxymethyl-CMP $\mathbf{3 b}$ (peak 2) and unmodified CMP 3a (peak 1); (d) unmodified UMP 4a.

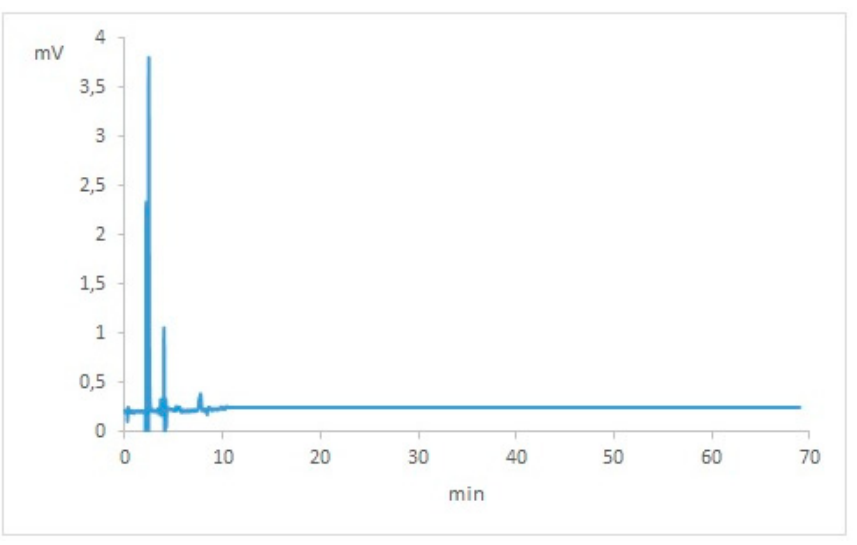

Figure A3. Chromatogram of no template control of the digestion reaction including S1 nuclease and its $1 x$ reaction buffer.

\section{Appendix B}

$\triangle \mathrm{Amp}$ was calculated between amplicons of mt-CO1. $\triangle \mathrm{Amp} \mathrm{M}-\mathrm{S}$ refers to the difference between $\mathrm{Ct}$ detected for $179 \mathrm{~b}$ amplicon and $60 \mathrm{~b}$ amplicon of mt-CO1, $\triangle \mathrm{Amp}$ L-S refers to the difference between Ct detected for $302 \mathrm{~b}$ amplicon and $60 \mathrm{~b}$ amplicon of mt-CO1, as already defined [15].

Table A1. $\triangle$ Amp of mt-CO1 gene for mouse livers samples.

\begin{tabular}{ccc}
\hline Specimen & $\begin{array}{c}\Delta \text { Amp M-S } \\
(\mathbf{6 0 - 1 7 9 )}\end{array}$ & $\begin{array}{c}\Delta \text { Amp L-S } \\
\mathbf{( 3 0 2 - 6 0 )}\end{array}$ \\
\hline Frozen & 1.00 & 2.93 \\
FF & 4.43 & 13.48 \\
BF & 5.63 & N.A. ${ }^{1}$ \\
RF & 1.48 & 10.05 \\
FFPE & 1.50 & 6.37 \\
BFPE & 10.41 & N.A. \\
RFPE & 1.44 & 6.87 \\
\hline
\end{tabular}

${ }^{1}$ N.A. not assessable 


\section{Appendix C}

In order to investigate on the effect of de-modification step of RNAs, RNA isolation by the use of the RNA isolation procedure for FFPE (See Material and method section) was carried out parallelly using 2 slides of $10 \mu \mathrm{m}$ thick slides of FFPE prostate cancer tissues. One replicate included the RNA de-modification step at $80^{\circ} \mathrm{C}$ for $1 \mathrm{~h}$, while the in the other the step was omitted. Although hm-AMP and hm-CMP were not detectable a reduction of the hm-GMP (up to ten times) was obtained after the de-modification (Figure A4). This step did not influence the BioAnalyzer analysis, which returned a RIN value of 2.3 for both (Figure A5).

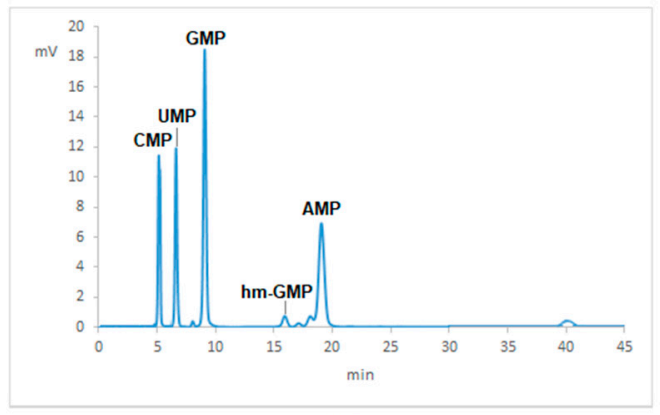

(a)

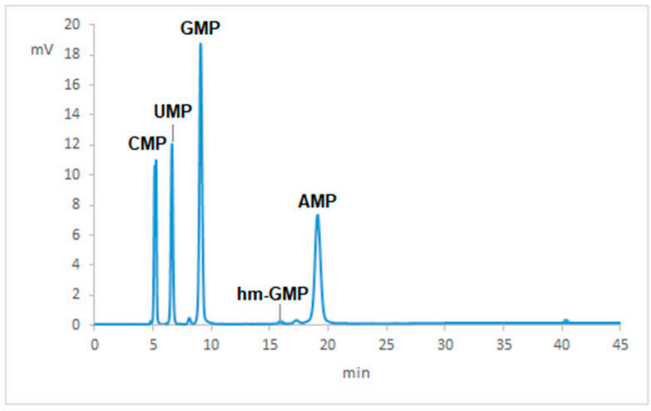

(b)

Figure A4. Chromatogram of: (a) prostate cancer FFPE tissue without RNA de-modification step and (b) with de-modification step.
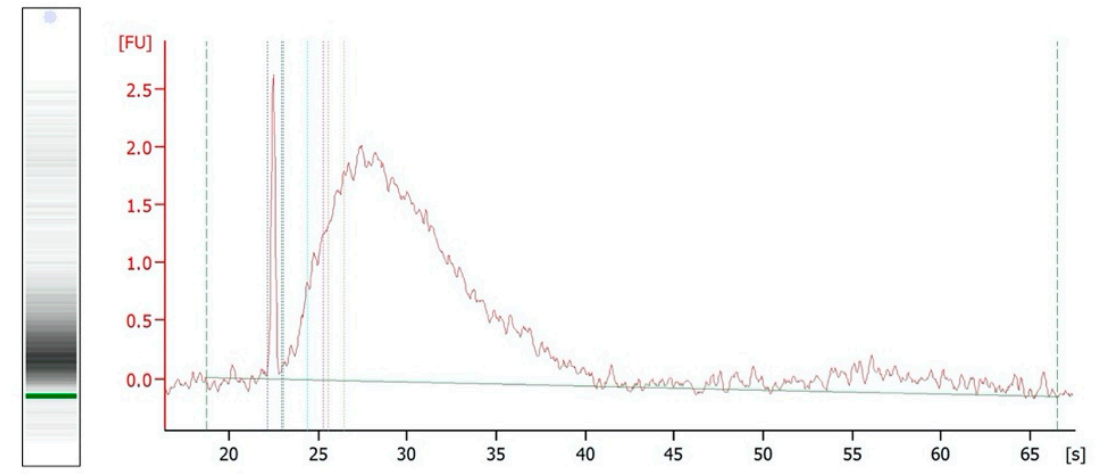

(a)
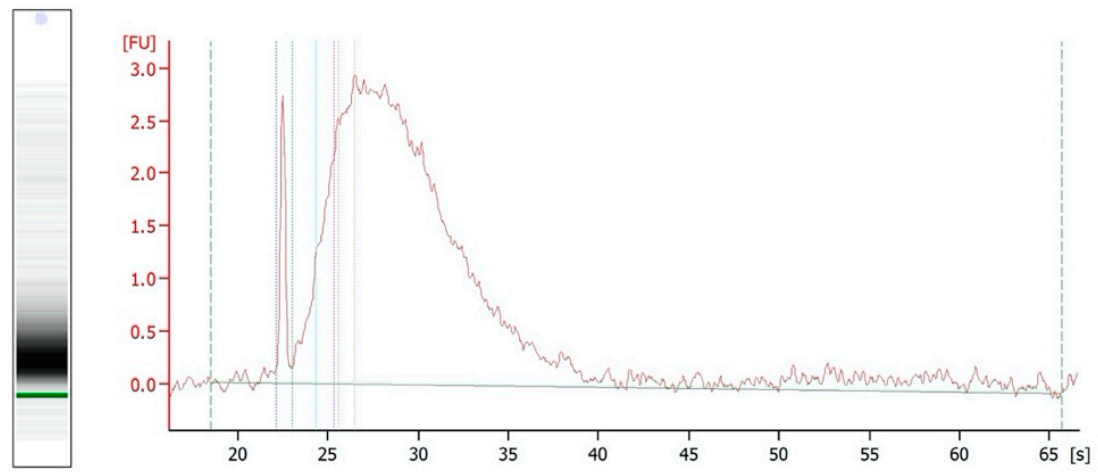

(b)

Figure A5. Output of the BioAnalyzer analysis of FFPE prostate cancer tissue (a) without RNA de-modification step and (b) with de-modification step. The image includes the gel-like image (left side) and the electropherogram (right side).

\section{References}

1. Bussolati, G.; Annaratone, L.; Medico, E.; D'Armento, G.; Sapino, A. Formalin fixation at low temperature better preserves nucleic acid integrity. PLoS ONE 2011, 6, e21043. [CrossRef] [PubMed] 
2. Azzalini, E.; De Martino, E.; Fattorini, P.; Canzonieri, V.; Stanta, G.; Bonin, S. Reliability of miRNA Analysis from Fixed and Paraffin-Embedded Tissues. Int. J. Mol. Sci. 2019, 20, 4819. [CrossRef] [PubMed]

3. Delfour, C.; Roger, P.; Bret, C.; Berthe, M.L.; Rochaix, P.; Kalfa, N.; Raynaud, P.; Bibeau, F.; Maudelonde, T.; Boulle, N. RCL2, a new fixative, preserves morphology and nucleic acid integrity in paraffin-embedded breast carcinoma and microdissected breast tumor cells. J. Mol. Diagn. 2006, 8, 157-169. [CrossRef] [PubMed]

4. Dotti, I.; Bonin, S.; Basili, G.; Nardon, E.; Balani, A.; Siracusano, S.; Zanconati, F.; Palmisano, S.; De Manzini, N.; Stanta, G. Effects of formalin, methacarn, and fineFIX fixatives on RNA preservation. Diagn. Mol. Pathol. 2010, 19, 112-122. [CrossRef] [PubMed]

5. Viertler, C.; Groelz, D.; Gundisch, S.; Kashofer, K.; Reischauer, B.; Riegman, P.H.; Winther, R.; Wyrich, R.; Becker, K.F.; Oelmuller, U.; et al. A new technology for stabilization of biomolecules in tissues for combined histological and molecular analyses. J. Mol. Diagn. 2012, 14, 458-466. [CrossRef]

6. Bonin, S.; Petrera, F.; Rosai, J.; Stanta, G. DNA and RNA obtained from Bouin's fixed tissues. J. Clin. Pathol. 2005, 58, 313-316. [CrossRef]

7. Masuda, N.; Ohnishi, T.; Kawamoto, S.; Monden, M.; Okubo, K. Analysis of chemical modification of RNA from formalin-fixed samples and optimization of molecular biology applications for such samples. Nucleic Acids Res. 1999, 27, 4436-4443. [CrossRef]

8. AbouHaidar, M.G.; Ivanov, I.G. Non-enzymatic RNA hydrolysis promoted by the combined catalytic activity of buffers and magnesium ions. Z. Naturforsch. C 1999, 54, 542-548. [CrossRef]

9. Crain, P.F. Preparation and enzymatic hydrolysis of DNA and RNA for mass spectrometry. Methods Enzymol. 1990, 193, 782-790. [CrossRef]

10. Dizdaroglu, M. Chemical determination of oxidative DNA damage by gas chromatography-mass spectrometry. Methods Enzymol. 1994, 234, 3-16. [CrossRef]

11. Lipkin, D.; Talbert, P.T.; Cohn, M. The Mechanism of the Alkaline Hydrolysis of Ribonucleic Acids. J. Am. Chem. Soc. 1954, 76, 2871-2872. [CrossRef]

12. Perret, D. HPLC of Small Molecules a Practical Approach; Lim, C.K., Ed.; Oxford IRL Press: Oxford, UK, 1986; pp. 221-225.

13. Adams, R.L.P.; Knowler, J.; Leader, D. (Eds.) The Biochemistry of Nucleic Acids, 11th ed.; Chapman \& Hall Ltd.: London, UK, 1992; ISBN 978-94-011-2290-0.

14. ISO 20166-1:2018. Molecular In Vitro Diagnostic Examinations-Specifications for Pre-Examination Processes for Formalin-Fixed and Paraffin-Embedded (FFPE) Tissue-Part 1: Isolated RNA. 2018. Available online: https://www.iso.org/standard/67179.html (accessed on 12 October 2020).

15. Bjorkman, J.; Svec, D.; Lott, E.; Kubista, M.; Sjoback, R. Differential amplicons (DeltaAmp)-a new molecular method to assess RNA integrity. Biomol. Detect. Quantif. 2016, 6, 4-12. [CrossRef] [PubMed]

16. Chung, J.Y.; Cho, H.; Hewitt, S.M. The paraffin-embedded RNA metric (PERM) for RNA isolated from formalin-fixed, paraffin-embedded tissue. Biotechniques 2016, 60, 239-244. [CrossRef] [PubMed]

17. Wehmas, L.C.; Wood, C.E.; Chorley, B.N.; Yauk, C.L.; Nelson, G.M.; Hester, S.D. Enhanced Quality Metrics for Assessing RNA Derived From Archival Formalin-Fixed Paraffin-Embedded Tissue Samples. Toxicol. Sci. 2019, 170, 357-373. [CrossRef]

18. Bjoerkman, J.; Kubista, M. Methods for Assessing RNA Quality. WO2013139860A1, 26 September 2013. Available online: https://patentscope.wipo.int/search/en/detail.jsf?docId=WO2013139860\&tab= PCTDESCRIPTION (accessed on 12 October 2020).

19. Srinivasan, M.; Sedmak, D.; Jewell, S. Effect of fixatives and tissue processing on the content and integrity of nucleic acids. Am. J. Pathol. 2002, 161, 1961-1971. [CrossRef]

20. Evers, D.L.; Fowler, C.B.; Cunningham, B.R.; Mason, J.T.; O’Leary, T.J. The effect of formaldehyde fixation on RNA: Optimization of formaldehyde adduct removal. J. Mol. Diagn. 2011, 13, 282-288. [CrossRef]

21. Wehmas, L.C.; Wood, C.E.; Gagne, R.; Williams, A.; Yauk, C.; Gosink, M.M.; Dalmas, D.; Hao, R.; O’Lone, R.; Hester, S. Demodifying RNA for Transcriptomic Analyses of Archival Formalin-Fixed Paraffin-Embedded Samples. Toxicol. Sci. 2018, 162, 535-547. [CrossRef]

22. Beland, F.A.; Fullerton, N.F.; Heflich, R.H. Rapid isolation, hydrolysis and chromatography of formaldehyde-modified DNA. J. Chromatogr. 1984, 308, 121-131. [CrossRef]

23. Fennell, T.R. Development of methods for measuring biological markers of formaldehyde exposure. Res. Rep. Health Eff. Inst. 1994, 67, 1-20. 
24. Karmakar, S.; Harcourt, E.M.; Hewings, D.S.; Scherer, F.; Lovejoy, A.F.; Kurtz, D.M.; Ehrenschwender, T.; Barandun, L.J.; Roost, C.; Alizadeh, A.A.; et al. Organocatalytic removal of formaldehyde adducts from RNA and DNA bases. Nat. Chem. 2015, 7, 752-758. [CrossRef]

25. McGhee, J.D.; von Hippel, P.H. Formaldehyde as a probe of DNA structure. I. Reaction with exocyclic amino groups of DNA bases. Biochemistry 1975, 14, 1281-1296. [CrossRef] [PubMed]

26. Rait, V.K.; Zhang, Q.; Fabris, D.; Mason, J.T.; O'Leary, T.J. Conversions of formaldehyde-modified $2^{\prime}$-deoxyadenosine $5^{\prime}$-monophosphate in conditions modeling formalin-fixed tissue dehydration. J. Histochem. Cytochem. 2006, 54, 301-310. [CrossRef] [PubMed]

27. Howat, W.J.; Wilson, B.A. Tissue fixation and the effect of molecular fixatives on downstream staining procedures. Methods 2014, 70, 12-19. [CrossRef] [PubMed]

28. Guillou, L.; Coindre, J.; Gallagher, G.; Terrier, P.; Gebhard, S.; de Saint Aubain Somerhausen, N.; Michels, J.; Jundt, G.; Vince, D.R.; Collin, F.; et al. Detection of the synovial sarcoma translocation $t(X ; 18)(S Y T ; S S X)$ in paraffin-embedded tissues using reverse transcriptase-polymerase chain reaction: A reliable and powerful diagnostic tool for pathologists. A molecular analysis of 221 mesenchymal tumors fixed in different fixatives. Hum. Pathol. 2001, 32, 105-112. [PubMed]

29. Bonin, S.; Stanta, G. Pre-analytics and tumor heterogeneity. N. Biotechnol. 2020, 55, 30-35. [CrossRef]

30. Hester, S.D.; Bhat, V.; Chorley, B.N.; Carswell, G.; Jones, W.; Wehmas, L.C.; Wood, C.E. Editor's Highlight: Dose-Response Analysis of RNA-Seq Profiles in Archival Formalin-Fixed Paraffin-Embedded Samples. Toxicol. Sci. 2016, 154, 202-213. [CrossRef]

31. Kashofer, K.; Viertler, C.; Pichler, M.; Zatloukal, K. Quality control of RNA preservation and extraction from paraffin-embedded tissue: Implications for RT-PCR and microarray analysis. PLoS ONE 2013, 8, e70714. [CrossRef]

32. Sanchez, I.; Betsou, F.; Culot, B.; Frasquilho, S.; McKay, S.C.; Pericleous, S.; Smith, C.; Thomas, G.; Mathieson, W. RNA and microRNA Stability in PAXgene-Fixed Paraffin-Embedded Tissue Blocks After Seven Years' Storage. Am. J. Clin. Pathol. 2018, 149, 536-547. [CrossRef]

33. Groelz, D.; Viertler, C.; Pabst, D.; Dettmann, N.; Zatloukal, K. Impact of storage conditions on the quality of nucleic acids in paraffin embedded tissues. PLoS ONE 2018, 13, e0203608. [CrossRef]

34. Dotti, I.; Bonin, S. DNase Treatment of RNA. In Guidelines for Molecular Analysis in Archive Tissues; Stanta, G., Ed.; Springer: Berlin/Heidelberg, Germany, 2011; pp. 87-90. ISBN 978-3-642-17890-0-18.

35. Nardon, E.; Donada, M.; Bonin, S.; Dotti, I.; Stanta, G. Higher random oligo concentration improves reverse transcription yield of cDNA from bioptic tissues and quantitative RT-PCR reliability. Exp. Mol. Pathol. 2009, 87, 146-151.

(C) 2020 by the authors. Licensee MDPI, Basel, Switzerland. This article is an open access article distributed under the terms and conditions of the Creative Commons Attribution (CC BY) license (http://creativecommons.org/licenses/by/4.0/). 